\title{
Does investor risk perception drive asset prices in markets? Experimental evidence
}

\author{
Jürgen Huber ${ }^{a, *}$, Stefan Palan ${ }^{\mathrm{a}, \mathrm{b}}$, Stefan Zeisberger ${ }^{\mathrm{c}, \mathrm{d}}$ \\ a Department of Banking and Finance, University of Innsbruck, Universitätsstraße 15, Innsbruck 6020, Austria \\ ${ }^{\mathrm{b}}$ Department of Banking and Finance, University of Graz, Universitätsstraße 15, Graz 8010, Austria \\ ' Institute for Management Research, Radboud University, Heyendaalseweg 141 Nijmegen 6525AJ, the Netherlands \\ ${ }^{\mathrm{d}}$ Department of Banking and Finance, University of Zurich, Plattenstrasse 14, Zurich 8032, Switzerland
}

\section{A R T I C L E I N F O}

\section{Article history:}

Received 27 January 2019

Accepted 10 September 2019

Available online 13 September 2019

\section{Keywords:}

Risk

Risk perception

Asset market

Experimental finance

Experimental economics

\begin{abstract}
A B S T R A C T
We explore how individual risk perception influences prices and trading behavior in a market setting. Specifically, our study lets experimental participants trade assets characterized by varying shapes of return distributions. While common mean-variance models predict identical prices for most of our assets, we find trading prices to differ significantly. Assets that are perceived as being less risky on average (despite having identical volatility) trade at significantly higher prices. Individually, traders who perceive a certain asset to be less risky are also net buyers on average. With regard to different risk measures, our results show that the probability of a loss is the strongest predictor of transaction prices and risk perception. All these results hold also for experienced traders and when traders can trade two assets at the same time.
\end{abstract}

(c) 2019 The Authors. Published by Elsevier B.V.

This is an open access article under the CC BY license. (http://creativecommons.org/licenses/by/4.0/)

\section{Introduction}

Building on a growing body of literature showing that individual risk perception is often driven by factors other than volatility, we are the first to explore whether and how risk perception influences prices and trading behavior in markets. In particular we test whether risk measures, such as volatility of returns, or rather subjectively perceived risk, drives asset prices; and if the driver is risk perception, to what extent and in what way it affects market prices.

Would, for example, a guarantee product that promises to pay back at least the amount invested, trade at a premium compared to other products with the same return volatility and expected return, because investors perceived it to be less risky? This would be a finding not covered by prominent finance models like Markowitz' (1952)) portfolio theory or the CAPM of Sharpe (1964), Lintner (1965) and Mossin (1966), where expected return, volatility of returns and the covariance of different assets are assumed to be the factors driving prices of risky assets.

Several studies in the judgment and decision making domain explore drivers of risk perception, mostly using complex gambles

\footnotetext{
* Corresponding author.

E-mail addresses: juergen.huber@uibk.ac.at (J. Huber), stefan.palan@uni-graz.at (S. Palan), s.zeisberger@fm.ru.nl (S. Zeisberger).
}

(Brachinger and Weber, 1997; Keller et al., 1986; Klos et al., 2005; Veld and Veld-Merkoulova, 2008; Zeisberger, 2016) or theoretical models (Diecidue and Van De Ven, 2008). However, several authors suggest that risk perception and thus, by extension, risktaking, is domain-specific and that settings where financial alternatives are framed as gambles may lead to different results regarding risk-taking behavior than settings where financial alternatives are framed as investment decisions. (see, e.g., Rettinger and Hastie, 2001; Weber et al., 2002; 2005; Baucells and Rata, 2006; Nosić and Weber, 2010; Weber et al., 2013). This implies that a pure gambling task is unlikely to be perceived in the same way as a (more complex) investment task and that results from the former may not hold for the latter.

Recent studies have thus studied more directly whether the most commonly used risk measure, volatility (usually expressed as the standard deviation of returns), is what investors, investment advisors and financial practitioners apply intuitively when evaluating risky assets. Nosić and Weber (2010), Weber et al. (2013), Bradbury et al. (2015) and Merkle (2018) demonstrate that volatility often plays only a minor role for risk perception and allocation decisions. ${ }^{1}$ In papers using a similar design to our own,

\footnotetext{
1 Ehm et al. (2018) outline possibilities to at least partially overcome the neglect of volatility in investment decisions. Earlier studies on investor risk perception include MacGregor et al. (1999), who ask financial experts to rate the riskiness
} 
Zeisberger (2018) and Holzmeister et al. (2019) let experimental subjects assess the riskiness of various return distributions. Both papers provide direct evidence that investors evaluate the risk inherent in asset return distributions mostly according to the probability of incurring a loss.

However, all of the results presented above are obtained at the individual as opposed to at the market level. In behavioral finance there is an ongoing debate about whether individual biases and preferences are relevant for market prices or whether arbitrage prevents them from having an effect (see, e.g., Gode and Sunder, 1993; Coval and Shumway, 2005; Barber et al., 2008; Shefrin, 2008; Heemeijer et al., 2009; Hommes, 2011; Hirshleifer, 2015). The transferability of individual results to market outcomes and to trading behavior in a market setting is not necessarily straightforward. The most common line of argument is that individual biases will usually cancel out, and even if not, that a few perceptive investors will drive prices to fundamentals. Yet Levy and Levy (2009) reach a different conclusion. They theoretically explore how asset prices and asset allocations would be affected by investors having non-standard preferences. Investors in their model follow a safety-first approach (originally proposed by Roy, 1952), which is equivalent to an explicit aversion against the probability of experiencing a loss. Levy and Levy's model yields asset allocations and market prices which differ from standard finance models. However, the heterogeneity across investors in risk perceptions and preferences makes it difficult to infer market predictions from results gained at the individual level. ${ }^{2}$

Against this background we are the first to directly test whether investor risk perception elicited at the individual level also plays a role in a market setting, in which prices are the result of demand and supply. In particular, we conduct laboratory experiments in which we present participants with different asset return distributions. This controlled setting allows us to hold mean return constant but vary a number of other characteristics across the distributions. This variation may induce differences in risk perception across assets between individuals. We let experimental subjects trade these assets in a continuous double auction market. Our setup allows us to compare market prices across assets. We are furthermore able to analyze to what extent individually-stated risk perception predicts market prices and individual trading behavior in markets. We thus aim to contribute to resolving the ongoing debate about whether and to what extent individual preferences, biases and perceptions influence market prices and trading behavior.

We find that individual risk perceptions indeed predict prices in asset markets: assets with higher average perceived riskiness are traded at significantly lower prices. We furthermore find that individually elicited risk perception also predicts traders' behavior in markets. Participants who state a comparatively low perceived riskiness for a given asset are more likely to be net buyers than are traders who state a comparatively high perceived riskiness, even though prices already reflect differences in perceived riskiness. Our findings are robust to analyzing different subsets of our data. The results also hold for experienced traders and when

of various general investment categories and document a substantial heterogeneity of different notions of risk, Koonce et al. (2005), who find that decision theory and behavioral variables both directly influence investors' risk assessments, and Unser (2000), who presents participants with hypothetical future price distributions of different stocks and observes that for future returns and a variable hypothetical holding period, risk is perceived mainly as the length of time a stock price remains below a previous reference point.

2 Related to our research question, experimental papers have examined portfolio choice and the empirical reliability of mean-variance frameworks. Ackert et al. (2016) for example find that in a setting where optimality is relatively easy to detect, individuals are much more likely to make decisions accordingly, and Kroll et al. (1988) find substantial inefficient choice behavior in a portfolio selection task. traders can trade two assets at the same time. With regard to the underlying driver of risk perception, we find the probability of incurring a loss, rather than more common risk measures, to explain 95 percent of the variation in perceived riskiness at the asset level. This in turn explains 94 percent of the variation in average trading prices in our markets. As Zeisberger $(2016,2018)$ show, it is important to distinguish between the expected loss, the magnitude of a loss and the probability of a loss. Neither the findings in Zeisberger (2018) nor our own can be explained by investors' loss aversion. Our results are thus distinct from the well-known findings of, e.g., Benartzi and Thaler (1995) for asset allocations and Barberis et al. (2001) or Ang et al. (2005) for asset prices.

\section{Design and implementation of the experiment}

\subsection{General aim and procedure}

We ran laboratory experiments to test whether risk perception affects market prices and trading behavior in experimental asset markets. The experiment started by the experimenter reading out loud, and the subjects following along on their own paper copies, general information about the experiment and specific instructions regarding the trading mechanism. This was followed by a trial trading period to train participants in operating the trading interface. Next, the experimenter read out loud, and the subjects followed along on their own paper copies, the instructions regarding the endowments, the assets to be traded, and the payout function. Then followed the main part of the experiment, in which different assets were traded one after the other (described in detail below). A questionnaire with socio-demographic items, risk- and loss-preference elicitation and financial literacy questions concluded the experiment. Subjects were then paid, in private and in cash, and left.

In the main part of the experiment we use eight different assets, each with a distinct return distribution (see Fig. 1 and the next subsection). Participants assess the risk of the first asset on a 7-point Likert scale (from 1 for lowest to 7 for highest perceived riskiness). After this assessment, fixed groups of eight subjects trade the asset for three minutes. After trading, participants move on to the second asset, assess its risk, followed by a trading round, etc., until the eighth asset. We elicit individuals' risk perceptions for each asset before trading since we do not want the perception data to be contaminated by the experience in the markets and since Zeisberger (2018) shows that asking for risk perception itself does not systematically influence the willingness to invest at the individual level in a way that would distort our marketlevel analyses.

\subsection{Asset return distributions}

To shed some light on the potential drivers of risk perception, our assets differ in terms of kurtosis, probability of incurring a loss, expected loss and skewness, as well as minimum and maximum return. Here we follow the design of Zeisberger (2018), and seven of our eight assets are also present in his study (he uses ten assets, of which we discard three which closely resemble others and which therefore are not suited for our purpose of inducing varying levels of perceived riskiness). The one additional asset we designed is asset KURTOSIS, which is leptocurtic, i.e., it is characterized by an excess kurtosis of 4.56. All distributions are depicted in Fig. 1 and their properties and main characteristics are outlined in Table 1. One main reason for following Zeisberger's approach is that he documents strong differences in risk perception, which is a necessary condition for finding any potential differences at the market level. 

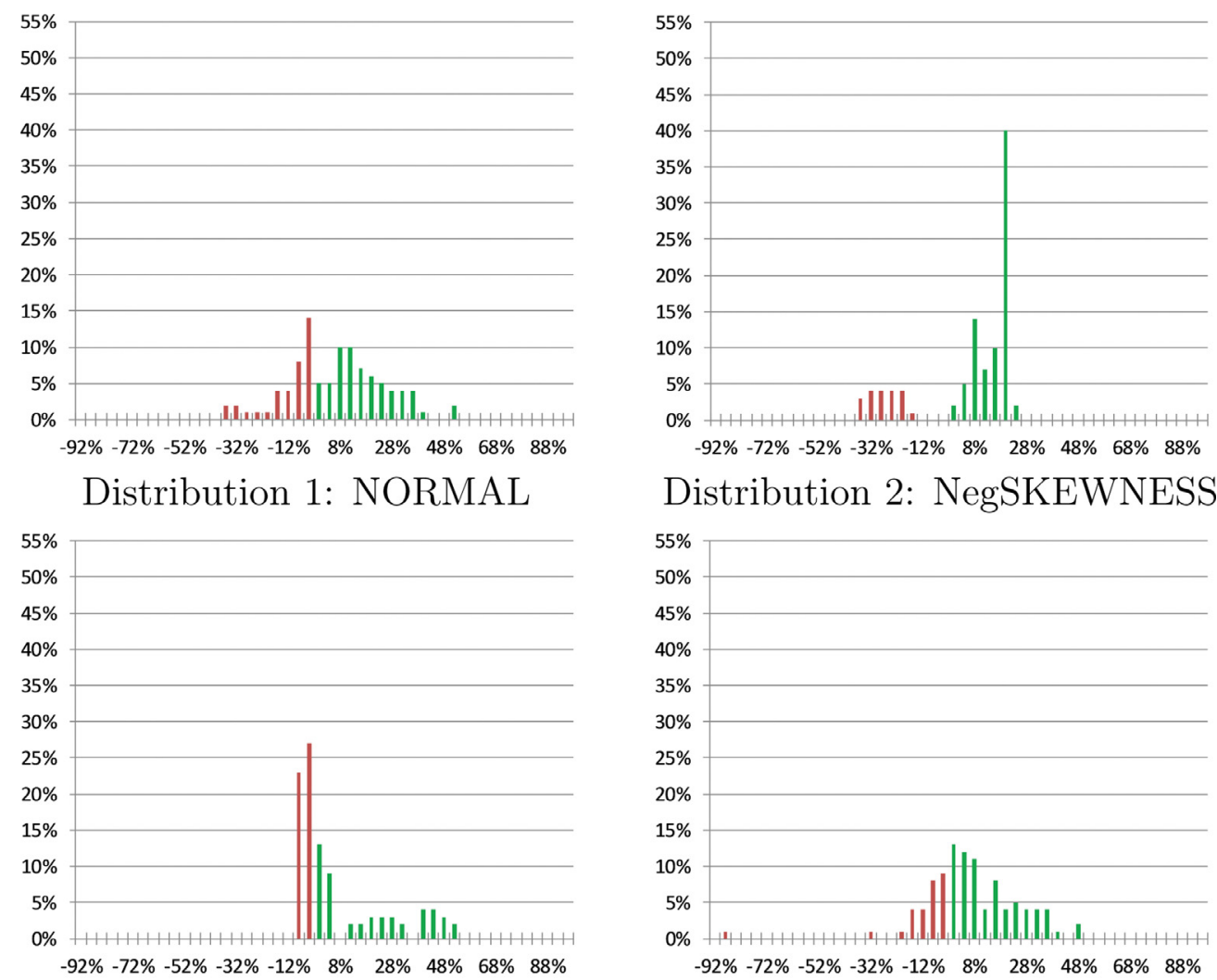

Distribution 2: NegSKEWNESS

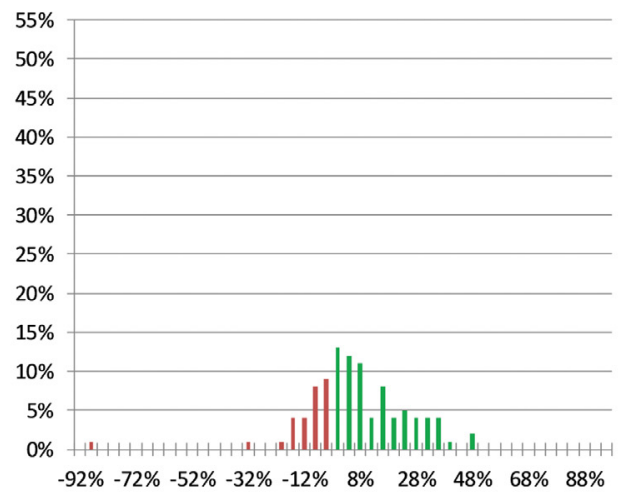

Distribution 3: PosSKEWNESS

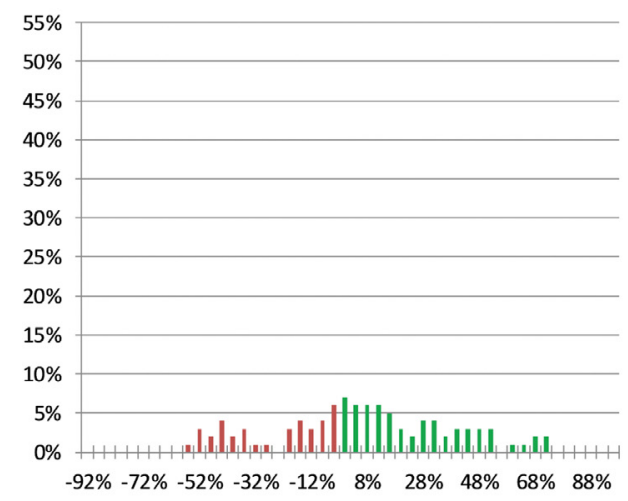

Distribution 4: BigLOSS

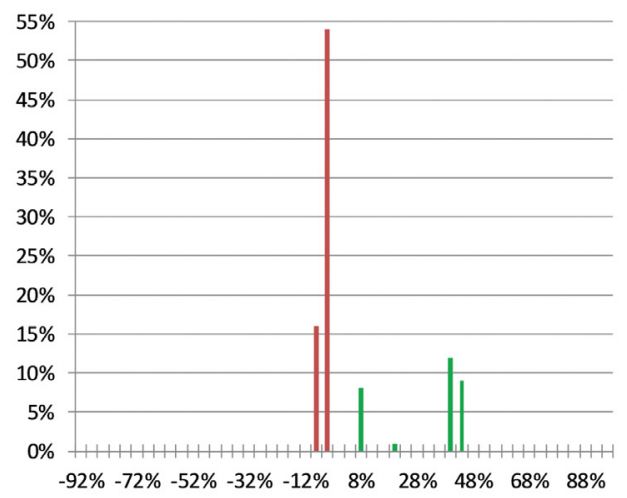

Distribution 5: WIDER

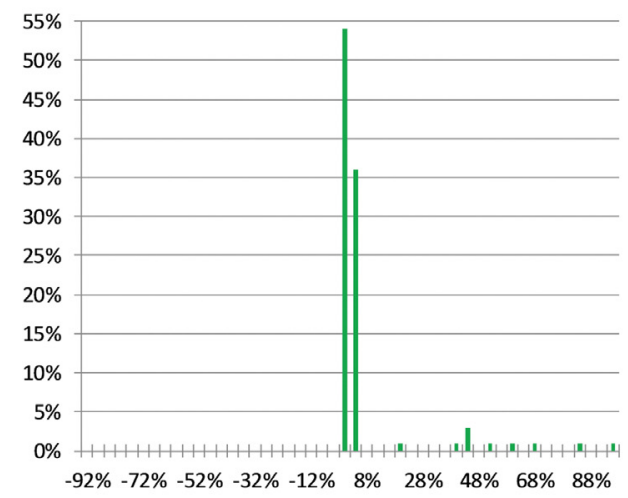

Distribution 7: NoLOSS

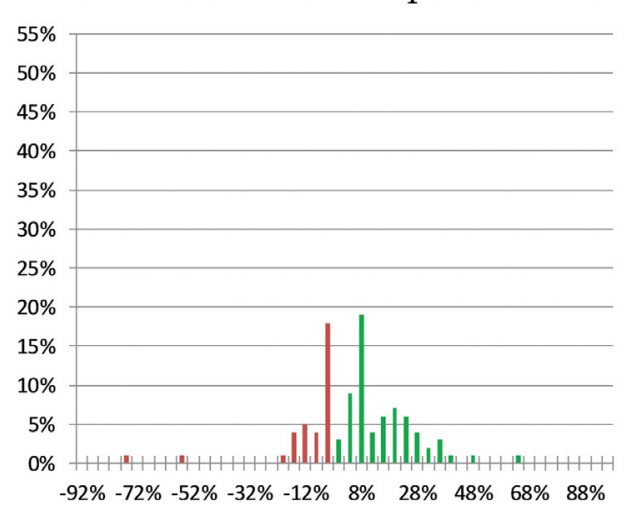

Distribution 8: KURTOSIS

Fig. 1. Return distributions of the eight assets used in the experiment. 
Table 1

Characteristics of the eight distributions used in the experiment. PLoss stands for the probability of incurring a loss and ELoss for the expected loss.

\begin{tabular}{llllllllll}
\hline Distribution & Mean & StdDev & Semivar & PLoss & ELoss & Skewness & Kurtosis & MinReturn & MaxReturn \\
\hline NORMAL & 0.082 & 0.181 & 0.178 & 0.370 & -0.038 & 0.002 & -0.024 & -0.360 & 0.550 \\
NegSKEWNESS & 0.082 & 0.178 & 0.280 & 0.200 & -0.051 & -1.256 & 0.098 & -0.350 & 0.240 \\
PoSSKEWNESS & 0.082 & 0.178 & 0.109 & 0.500 & -0.021 & 1.276 & 0.204 & -0.060 & 0.540 \\
BigLOSS & 0.084 & 0.182 & 0.185 & 0.280 & -0.031 & -0.985 & 5.442 & -0.850 & 0.500 \\
WIDER & 0.080 & 0.313 & 0.306 & 0.370 & -0.089 & 0.002 & -0.527 & -0.550 & 0.750 \\
FrequentLOSS & 0.080 & 0.184 & 0.108 & 0.700 & -0.020 & 1.294 & -0.171 & -0.050 & 0.460 \\
NoLOSS & 0.079 & 0.179 & 0.063 & 0.000 & 0.000 & 3.266 & 10.544 & 0.000 & 0.990 \\
KURTOSIS & 0.081 & 0.182 & 0.178 & 0.340 & -0.032 & -0.729 & 4.561 & -0.740 & 0.660 \\
\hline
\end{tabular}

Our eight different return distributions are selected such that, relative to the nominal buyback value (BBV) of 100 , each has a mean return of close to 8 percent. This fact was clearly communicated to our participants three times in the instructions. All other characteristics of the assets' return distributions were only communicated graphically, such that subjects who wanted to condition their decisions on, e.g., risk measures like variance or kurtosis, had to estimate these from the histogram of returns.

Importantly, the standard deviation of seven of the eight assets is approximately 18 percent, hence potential differences between trading prices of these seven assets cannot come from differences in this canonical risk measure. Only asset WIDER is designed to have a higher standard deviation of 31 percent. This allows us to study the effect of a variation in volatility on risk perception. Asset NORMAL is approximately normally distributed. Asset NegSKEWNESS displays highly negative skewness of -1.256 , PosSKEWNESS highly positive skewness of +1.276 . Asset BigLOSS stands out with the possibility of losing up to 85 percent. Asset FrequentLOSS is characterized by 70 percent of cases leading to (moderate) losses, while asset NoLOSS never incurs losses (but also offers only small gains). Finally, asset KURTOSIS has excess kurtosis of 4.56 .

\subsection{Trading environment}

The trading environment uses a continuous double auction mechanism with open order book. ${ }^{3}$ Participants can submit any combination of limit and/or market orders. The order book is emptied before the beginning of each period and provides information about prices and quantities of outstanding orders. Unexecuted limit orders can be canceled without cost and at any time, and orders are executed according to price, followed by time, priority. Shorting stocks and borrowing money is not possible. No interest is paid on taler (experimental currency) holdings and there are no transaction costs. Assets live for a single period and are bought back by the experimenter after market closing at the buyback value (BBV), which is the same for all traders. There are no other cash flows originating from assets. The BBV consists of the nominal buyback value of $100 \pm$ a return drawn from the respective asset's known return distribution with a mean of close to 8 percent (see Fig. 1 and Table 1). Hence, the expected payoff (and risk-neutral BBV) of each asset is 108 (rounded).

Each trader starts the experiment with an endowment of 5 assets and 800 taler. Cash and asset holdings are reset to these values at the beginning of each subsequent period. The ratio of outstanding talers to the value of outstanding assets, commonly referred to as the cash-to-asset ratio, thus is 1.48 in all periods. This ensures that traders are able to make transactions at reasonable frequencies and prices but it is also reasonably low to avoid biasing our results by cash endowment effects (see Kirchler et al., 2012,

\footnotetext{
${ }^{3}$ See the online appendix for the experimental instructions and screenshots of the trading environment.
}

Noussair and Tucker, 2016 and the references therein for evidence on the effect of cash endowments on mispricing).

\subsection{Questionnaire and payment}

After subjects have concluded risk assessment and trading of the eight assets, we ask them to answer the financial literacy questions 2, 3, 4, 7, 10, 12, and 16 of van Rooij et al. (2011). Following this step, subjects fill in a questionnaire eliciting their gender, age, nationality, employment status, major and type of study program. The questionnaire then asks the general and financial risk preference questions of Dohmen et al. (2011) and patience and loss preference questions modelled after the general risk preference question. ${ }^{4}$

Traders' payoffs in the experiment are based on their wealth $\left(W_{p, T}\right)$ determined at the end (time $\left.T\right)$ of a period $(p)$, with asset holdings evaluated at the realized BBV. To avoid diversification effects over the eight periods, the experimenter rolls an eightsided die after the final period to determine one period that is to be payoff-relevant for all traders in the session. All this is public knowledge. Given this incentive scheme and the zero-sum nature of the design, an inactive trader's period earnings depend only on the realization of BBV. At the expected value of 108 taler per asset, traders earn $5 \cdot 108+800=1340$ taler, or $€ 13.40$ on average from the trading phase (for subjects' payoffs at the end of the experiment, 100 taler equal $€ 1.00$ ). Finally, the computer randomly chooses one of the financial literacy questions and subjects earn an additional $€ 1.00$ if their answer on this question was correct.

\subsection{Robustness experiments}

To further explore the stability of our findings, we report on classroom sessions of a treatment we will title RETURN and on two other robustness check treatments labelled EXPERIENCE and TWO-MARKETS. ${ }^{5}$ In treatment RETURN, instead of asking subjects to answer the question "How risky do you perceive this security to be?" we ask "How attractive do you perceive the returns of this security to be?". In treatment EXPERIENCE we let subjects trade each asset for three consecutive periods and we do not elicit subjects' risk perceptions. We furthermore limit the set of assets to NoLOSS and FrequentLOSS, as these were the assets with the lowest and, respectively, highest, perceived riskiness. In treatment TWO-MARKETS, subjects trade the assets NoLOSS and FrequentLOSS simultaneously - one in the upper half of the screen, the other in the lower half. They do so for three periods. The three extra treatments are described in more detail in Sections 3.4.2 through 3.4.4.

\footnotetext{
${ }^{4}$ All of these questions use a Likert scale ranging from 0 to 10 as in, for example 0 or "Not at all willing to take risks" to 10 or "Very willing to take risks".

${ }^{5}$ We thank an anonymous reviewer for suggesting these latter two treatments.
} 


\subsection{Experimental organization}

We conducted the experiment at the Innsbruck EconLab in January 2017 (main experiment) and May 2019 (treatments EXPERIENCE and TWO-MARKETS) and at the MaxJungLab Graz in April 2017 and 2018 (treatment RETURN). For each session in Innsbruck we recruited 24 subjects with hroot (Bock et al., 2014) from a standard student subjects pool, for a total of 264 subjects. For each of the five sessions in Graz we recruited between 5 and 11 (average 8.6) subjects in a PhD-level class Experimental Methods, for a total of 43 subjects. In each session of the main experiment and of treatment EXPERIENCE we ran three parallel batches with eight subjects each forming one market. In the five sessions of treatment RETURN, between five and eleven subjects formed one market. In robustness check treatment TWO-MARKETS, twelve subjects formed one market. Hence, each of our assets in the main experiment was traded in 12 separate markets, in RETURN in 5 markets, in EXPERIENCE in 9 markets and in TWO-MARKETS in 10 markets. The software was implemented using GIMS v7.4.11 (Palan, 2015) in z-Tree v3.6.7 (Fischbacher, 2007). The experimental sessions lasted between 45 and 60 min and the average payment was $€ 13.60$ per subject in the main experiment, $€ 13.98$ in RETURN, $€ 12.19$ in EXPERIENCE and $€ 13.13$ in TWO-MARKETS.

\section{Results}

We start by presenting results on individual risk perception and then turn to market prices and trading volume. Finally, we explore the drivers of individual trading behavior in our markets. The data analysis was conducted in $R$ v3.5.1 (R Core Team, 2018), using the z-Tree import script described in Kirchkamp (2019) and the table output of Leifeld (2013).

\subsection{Individual risk assessment}

In each period, before trading started, subjects first had to individually assess the perceived riskiness of the asset on a 7-point Likert scale, as in Zeisberger (2018). ${ }^{6}$ As seven of our eight assets are also in the sample of Zeisberger's study, this task can be seen as a replication of this part of his work. The main finding in his paper is that the "probability of losing" is the most important determinant of what people perceive as risk, and our results clearly confirm this. As Fig. 2 and Table 2 show, "probability of a loss" is the only variable significantly driving risk perception in our experiment. Each of the seven panels of Fig. 2 shows one of seven potential risk drivers on the horizontal axis and average risk perception (across all 96 subjects) on the vertical axis. While most of the potential risk drivers show no clear pattern, the "probability of a loss" stands out with a clear upward trend. The higher the probability of experiencing a loss, the higher the perceived riskiness of the asset. With an $R^{2}$ of 0.958 the linear trend is a very good fit for the data. While this analysis is conducted only at the aggregate level, individual data regressions confirm these findings (see below for details). ${ }^{7}$ In Fig. 2, kurtosis also seems to be a driver of perceived risk. However, this is mostly due to the fact that the asset with

\footnotetext{
${ }^{6}$ Despite their atheoretical nature, Likert scales are frequently used in assessing (investor) risk perception; see, for example, Nosić and Weber (2010) and Weber et al. (2002, 2005). Alternative measures, such as estimating return volatility, require a higher level of statistical understanding and might not capture what (retail) investors think of as riskiness.

7 Figs. A.4 and A.5 in the appendix present the same data without averaging across subjects, once for all periods and once excluding data from the first period. While the individual period data is of course more noisy, the relationship between the probability of a loss and the perceived riskiness is still very strong $\left(R^{2}=0.77\right.$ in both figures).
}

Table 2

Regressions of RiskPerception (per trader and asset) on distribution characteristics. StdDev stands for standard deviation, PLoss for probability of a loss, ELoss for expected loss in case of a loss, and MinReturn for the minimum return possible.

\begin{tabular}{lll}
\hline & OLS & Subject fixed effects \\
\hline Intercept & $4.783^{* *}$ & \\
& $(2.063)$ & \\
StdDev & -19.017 & -19.017 \\
& $(16.393)$ & $(16.233)$ \\
Semivar & -10.520 & -10.520 \\
& $(19.113)$ & $(18.927)$ \\
PLoss & $5.434^{* * *}$ & $5.434^{* * *}$ \\
ELoss & $(1.453)$ & $(1.438)$ \\
& -75.537 & -75.537 \\
Skewness & $(66.911)$ & $(66.258)$ \\
& 0.097 & 0.097 \\
Kurtosis & $(1.008)$ & $(0.998)$ \\
& 0.049 & 0.049 \\
MinReturn & $(0.204)$ & $(0.202)$ \\
& 0.185 & 0.185 \\
$\mathrm{R}^{2}$ & $(2.982)$ & $(2.953)$ \\
Adj. $\mathrm{R}^{2}$ & 0.418 & 0.509 \\
Num. obs. & 0.412 & 0.433 \\
\end{tabular}

${ }^{* * *} p<0.01,{ }^{* *} p<0.05,{ }^{*} p<0.1$. Standard errors, clustered at the subject level (White), in parentheses..

no possible losses was also the one with the highest excess kurtosis of 10.54 . Volatility, by contrast, hardly seems to influence risk perception. This can be seen when contrasting assets NORMAL and WIDE, which are similar in terms of all other risk measures, but differ substantially in terms of standard deviation. A pairwise comparison reveals these distributions' average risk perception scores to be nearly identical at 4.19 (WIDE) and 4.28 (NORMAL). Furthermore, while seven assets have almost identical standard deviations of around 18 percent, their perceived riskiness varies from 1.3 to 5.9 .

In an additional analysis, shown in Table 2, we use "perceived riskiness" as the explained and seven possible risk drivers (standard deviation, semivariance, probability of a loss, expected loss, skewness, kurtosis, and minimum return) as the explanatory variables in two regressions. We find that only the coefficient of the probability of a loss (PLoss) is significant $(p<0.01)$ and that kurtosis shows no significant effect, confirming our individual correlation results, which highlighted "probability of a loss" as the main and only significant factor driving perceived riskiness in our experiment. This is in line with, and thus successfully replicates, the findings of Zeisberger (2018). Note again that loss aversion (as in Tversky and Kahneman, 1992) cannot explain the results, as shown in both Zeisberger (2018) and Holzmeister et al. (2019). Their and our findings indicate that investors seem to care more about the loss likelihood rather than about the magnitude of losses.

\subsection{Market data}

After the individual risk assessment task, subjects trade in a continuous double auction market for three minutes in each period. Each asset was traded for one period in each of the 12 sessions, so we have a total of 12 average period prices per asset. We observe quite active trading, with an average of 24 transactions per market - one every $7.5 \mathrm{~s}$. Average total trading volume per subject is 6.092 assets (females 6.602 vs. males 5.489), and the average absolute net change in subjects' asset balances is 2.984 (2.752 vs. 3.259). We observe trading prices in the individual markets which 

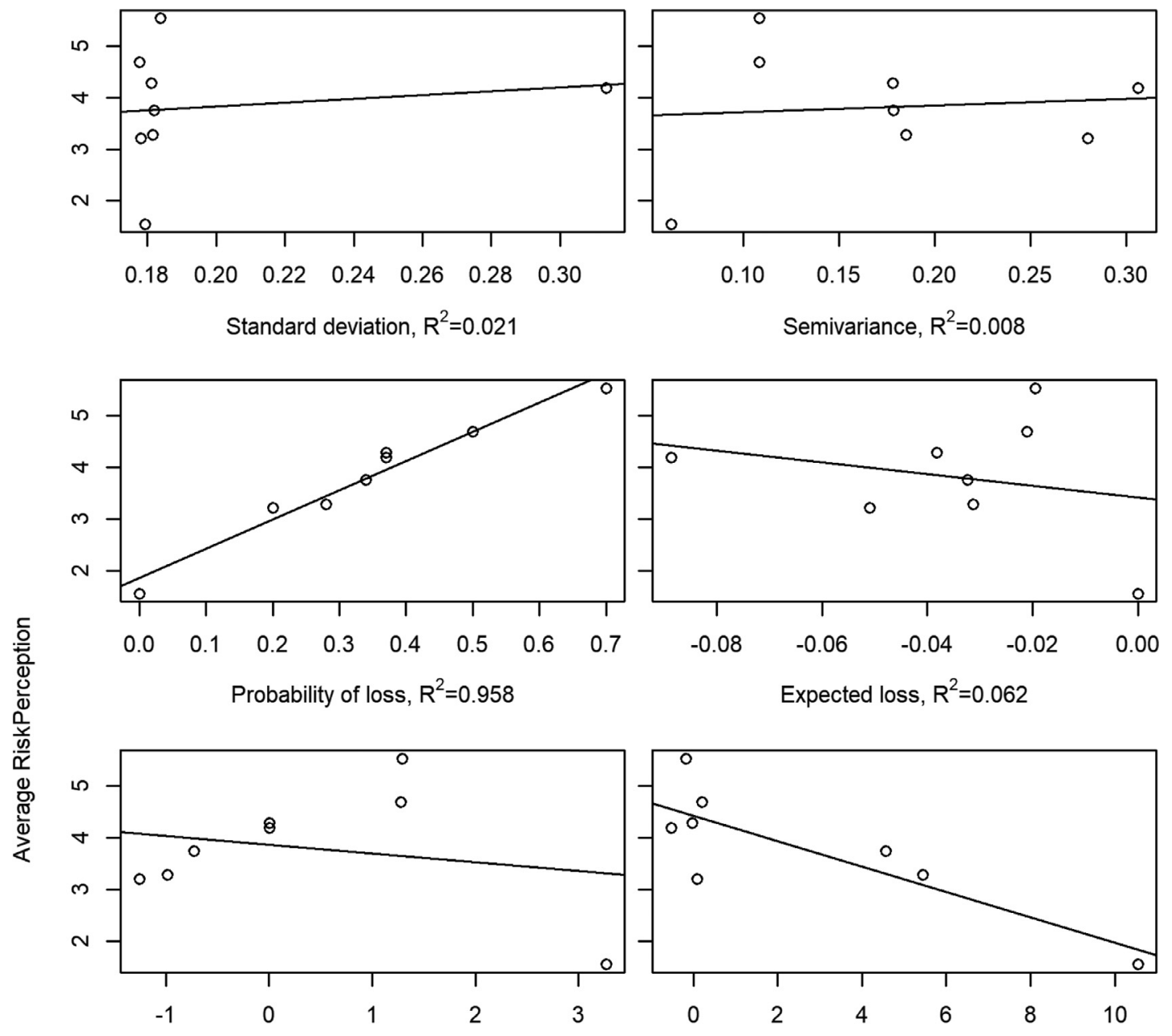

Skewness, $\mathrm{R}^{2}=0.046$

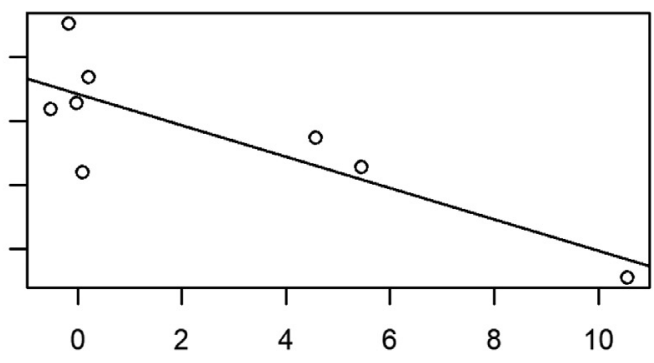

Kurtosis, $R^{2}=0.683$

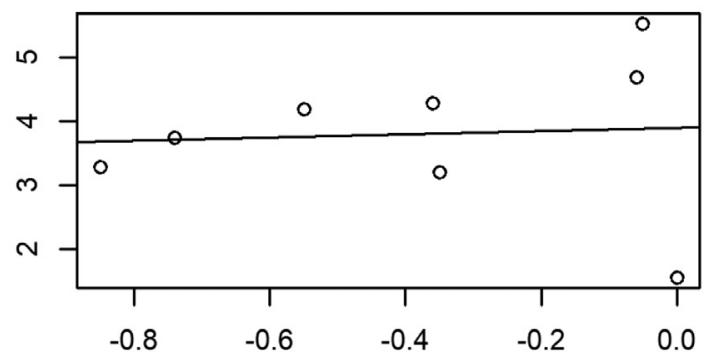

Minimum return, $\mathrm{R}^{2}=0.005$

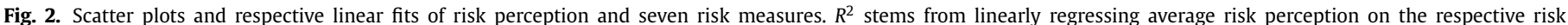
measure.

mostly stay between 95 and 135 talers, with a few prices outside of these bounds. ${ }^{8}$

We first present market-level data on risk perception, prices and trading volume. We then proceed to a lower aggregation level, analyzing how an individual's risk perception and willingness to

\footnotetext{
8 The only major outlier occurred in the first period of session 7, in which the asset NORMAL was traded. Here the average price was 253 talers and trading volume was comparatively low (14 trades). Given the magnitude of this exceptional outlier combined with the fact that it occurred in the first trading round and with low volume, we decided to discard it from the data analysis of prices, hence for asset NORMAL we have only 11 average period prices in all analyses, tables and figures.
}

invest translates into actual actions in the market and how this affects prices.

The first and most prominent question we are interested in is whether market prices are influenced by investors' average risk perception, or whether such perceptions are cancelled out in a market context. This could come about for example when the most active or sophisticated traders were to drive prices towards the fundamental value (identical across assets at 108). At the highest aggregation level, we compare average risk perception for an asset across all subjects with average prices across all sessions.

As depicted in Fig. 3, we see clearly that average risk perception drives prices, with higher perceived riskiness leading to markedly lower prices. The differences in average prices - ranging from 100 


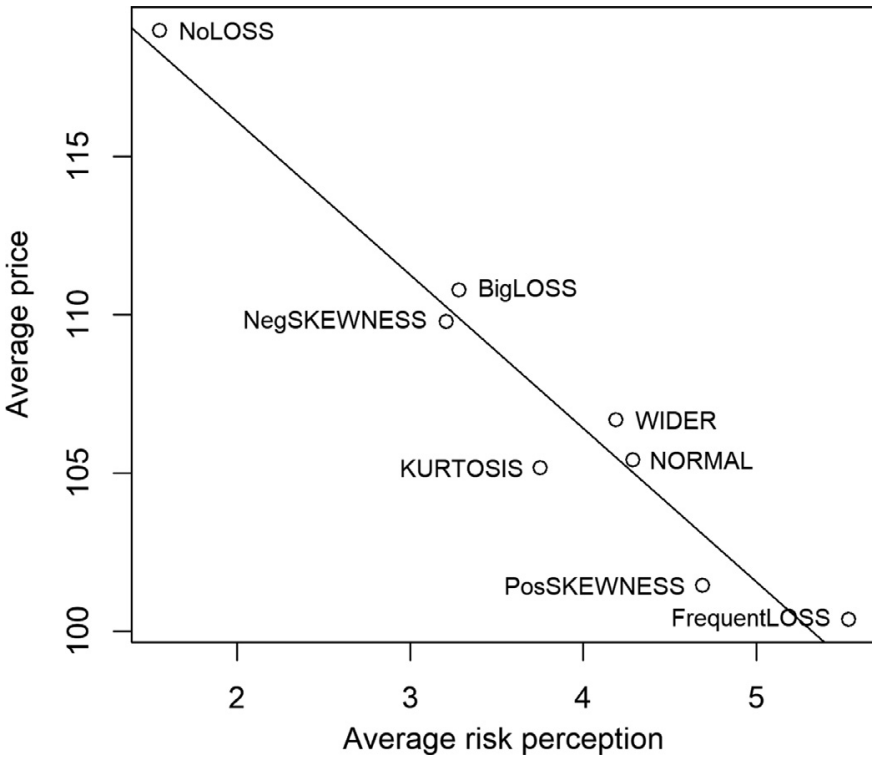

Fig. 3. Distribution of average prices over average risk perception. Aggregate data per asset, averaged over all markets. Each small circle represents one of the eight traded assets.

to 119 - are considerable and, as shown later, statistically significant. With an $R^{2}$ of 0.944 , the relation between average risk perceptions and average trading prices is very strong. Given the riskneutral BBV of about 108 for each asset, we find average prices to deviate by roughly \pm 9 percent, depending on perceived riskiness. ${ }^{9}$

Note that the return distributions we show to subjects are based on profits and losses relative to 100 and that the expected return is around 8 percent for each asset, leading to a risk-neutral price of 108 for each asset. At this price, however, asset NoLOSS can of course incur losses relative to the purchasing price. If, for example, a participant purchases the asset for 108 and the realized return is then 2 percent of the nominal BBV of 100, the subject receives only 102 . As we observe an average trading price of 119 for asset NoLOSS, subjects purchasing this asset at this price should actually expect to incur losses in about 80 percent of all cases (as 80 percent of the possible realizations are below 19 percent return). However, we find most subjects to be either ignorant of this fact or ready to accept the potential losses associated with the asset, thus keeping prices at the comparatively high levels we observe. Similar arguments hold for other assets. For example, asset FrequentLOSS has a loss probability of zero if bought at prices below 95 , as the largest loss for this asset is -5 percent.

Table 3 shows OLS regressions of average and median prices, trading volume, and trading price volatility on average risk perception and several other potentially relevant variables. Regarding our main outcome of interest, market prices (data columns 1 to 4 ), we find that participants' average risk perception in a market is the main driver of prices (average as well as median). If average risk perception is higher by 1 , average prices are lower by 4.326 , median prices by 4.961 . With a maximum difference in average risk perception of 3.979 between our assets, this accords to a maximum average price difference of 18.598 (21.584 for median prices), in line with our analysis above. Higher dispersion of risk perception between individuals within a market (as opposed to average risk perception) may conceivably also influence market prices, since it could be seen as a measure of market participant uncertainty. Yet

\footnotetext{
${ }^{9}$ Figure OA.4 in the appendix shows the same relationship with data from the 96 individual markets. The four panels show results for the full dataset and for three robustness checks.
}

we find that the standard deviation ${ }^{10}$ of subjects' risk perception scores in a market does not correlate significantly with average or median prices. Our results are also robust to controlling for averages of financial literacy, financial risk tolerance, and loss aversion (data columns 2 and 4 of Table 3). Including these control variables increases $R^{2}$ only marginally for average and median prices.

With regard to trading volume (data columns 5 and 6) our results indicate no significant joint variation with average risk perception or the dispersion of individuals' risk perception scores within a market. For the latter, we find a positive but insignificant coefficient. Trading volume, however, depends on the gender composition and loss preferences. We find lower trading volume in markets with higher proportions of men and with higher average loss aversion of market participants. For trading volume, $R^{2}$ increases from essentially zero to 0.296 when including the control variables, with average loss aversion and the proportion of female traders in a market as drivers.

Turning to price volatility in a market (data columns 7 and 8) we do not find any effects of average risk perception or its dispersion. Volatility is only influenced by the proportion of female traders and average financial literacy. A greater proportion of female traders and higher average financial literacy in a market correlate with lower volatility.

The main takeaway from Table 3 is that prices are strongly influenced by average risk perception, with higher perceived riskiness leading to lower prices. Risk perception dispersion does not influence market prices or trading volume, but gender and loss aversion do. Hence, in the contest of ideas of whether individual preferences and perceptions are washed out or influence prices, our results clearly support the latter position.

\subsection{Individual trading behavior and profits}

When we turn to individual trading behavior in our markets, one key question is whether subjects' final asset holdings are driven by their respective risk perceptions, i.e., whether those traders within a market who perceive a given asset as being comparatively more risky sell units of this asset to those traders who perceive it as being comparatively less risky. Table 4 shows that the data support this conjecture: final asset holdings are highly significantly negatively related to a trader's perception of asset riskiness. Thus, risk perception clearly influences individual trading behavior in our markets.

In the second data column of Table 4 we see that financial literacy, financial risk tolerance, and financial loss tolerance all show positive coefficients, even though only financial literacy's is significant. The last column reveals that women's trades differ from men's: female subjects are net sellers on average with 0.694 assets per period, while men purchase a net average of 0.822 assets ( $p$ value $=0.000$; note that we had more female than male participants - 52 vs. 44 , respectively).

When we investigate this result in more detail, we find evidence for a gender effect in trading behavior that does not disappear when controlling for risk perception (averages for females vs. males: 4.730 vs. $4.318 ; t(92.664)=1.152, p=0.252$ ), financial literacy score (3.962 vs. $4.500 ; t(93.242)=-2.161, p=0.033$ ), financial risk tolerance $(2.385$ vs. $5.159 ; t(84.16)=-5.594, p=0.000)$ or financial loss aversion (4.558 vs. $5.545 ; t(93.978)=-1.939, p=$ 0.056).

To properly analyze subjects' profits, we take each subject's holdings of cash and assets at the end of each period. We then aggregate them to a variable PeriodEndWealth by valuing the final asset holdings with the asset's expected ending value of around 108.

\footnotetext{
10 Regressions using the range of risk perception scores in a market instead of the standard deviation yield essentially identical results.
} 
Table 3

OLS regressions of average and median prices as well as trading volume and price volatility on average risk perception, standard deviation of risk perception, and on market-level averages of subject characteristics.

\begin{tabular}{|c|c|c|c|c|c|c|c|c|}
\hline & AvgPrice & AvgPrice & MedianPrice & MedianPrice & Volume & Volume & PriceSD & PriceSD \\
\hline (Intercept) & $\begin{array}{l}121.916 * * * \\
(9.299)\end{array}$ & $\begin{array}{l}85.498 \\
(98.131)\end{array}$ & $\begin{array}{l}124.375^{\text {**** }} \\
(9.979)\end{array}$ & $\begin{array}{l}97.373 \\
(97.666)\end{array}$ & $\begin{array}{l}24.155^{* * * *} \\
(4.738)\end{array}$ & $\begin{array}{l}82.417^{*} \\
(47.275)\end{array}$ & $\begin{array}{l}12.744^{* * *} \\
(4.013)\end{array}$ & $\begin{array}{l}126.457^{* * *} \\
(46.942)\end{array}$ \\
\hline AvgRiskPerception & $\begin{array}{l}-4.326^{* *} \\
(1.812)\end{array}$ & $\begin{array}{l}-3.835^{*} \\
(2.083)\end{array}$ & $\begin{array}{l}-4.961 \text { ** } \\
(2.007)\end{array}$ & $\begin{array}{l}-4.510^{*} \\
(2.311)\end{array}$ & $\begin{array}{l}-0.847 \\
(0.929)\end{array}$ & $\begin{array}{l}-1.119 \\
(0.741)\end{array}$ & $\begin{array}{l}-1.116 \\
(0.930)\end{array}$ & $\begin{array}{l}-1.346 \\
(1.075)\end{array}$ \\
\hline RiskPerception.SD & $\begin{array}{l}1.598 \\
(3.161)\end{array}$ & $\begin{array}{l}0.790 \\
(2.837)\end{array}$ & $\begin{array}{l}2.212 \\
(3.122)\end{array}$ & $\begin{array}{l}1.286 \\
(2.790)\end{array}$ & $\begin{array}{l}2.884 \\
(2.177)\end{array}$ & $\begin{array}{l}2.162 \\
(2.187)\end{array}$ & $\begin{array}{l}0.761 \\
(2.683)\end{array}$ & $\begin{array}{l}0.535 \\
(2.695)\end{array}$ \\
\hline PropFemale & & $\begin{array}{l}5.309 \\
(27.128)\end{array}$ & & $\begin{array}{l}7.466 \\
(26.983)\end{array}$ & & $\begin{array}{l}21.135^{*} \\
(12.302)\end{array}$ & & $\begin{array}{l}-23.818^{* *} \\
(10.207)\end{array}$ \\
\hline AvgFinLitScore & & $\begin{array}{l}-3.133 \\
(16.975)\end{array}$ & & $\begin{array}{l}-3.897 \\
(16.576)\end{array}$ & & $\begin{array}{l}-1.876 \\
(7.719)\end{array}$ & & $\begin{array}{l}-15.756^{* *} \\
(6.936)\end{array}$ \\
\hline AvgRiskFinancial & & $\begin{array}{l}4.018 \\
(2.966)\end{array}$ & & $\begin{array}{l}3.900 \\
(2.995)\end{array}$ & & $\begin{array}{l}0.400 \\
(3.321)\end{array}$ & & $\begin{array}{l}-3.502 \\
(2.681)\end{array}$ \\
\hline AvgLossAversion & & $\begin{array}{l}5.866 \\
(9.139)\end{array}$ & & $\begin{array}{l}4.610 \\
(9.005)\end{array}$ & & $\begin{array}{l}-11.597^{* * * *} \\
(2.140)\end{array}$ & & $\begin{array}{l}-3.884 \\
(2.387)\end{array}$ \\
\hline $\mathrm{R}^{2}$ & 0.093 & 0.151 & 0.102 & 0.150 & 0.024 & 0.296 & 0.011 & 0.122 \\
\hline Adj. $R^{2}$ & 0.073 & 0.093 & 0.083 & 0.092 & 0.002 & 0.248 & -0.011 & 0.063 \\
\hline Num. obs. & 95 & 95 & 95 & 95 & 95 & 95 & 95 & 95 \\
\hline RMSE & 16.585 & 16.404 & 17.937 & 17.849 & 9.523 & 8.269 & 13.048 & 12.565 \\
\hline
\end{tabular}

${ }^{* * *} p<0.01,{ }^{* *} p<0.05,{ }^{*} p<0.1$. Standard errors, clustered at the session level, in parentheses.

Table 4

OLS regressions of final asset holdings on RiskPerception and control variables .

\begin{tabular}{|c|c|c|c|}
\hline & Final asset holdings & Final asset holdings & Final asset holdings \\
\hline Intercept & $\begin{array}{l}6.022^{* * *} \\
(0.317)\end{array}$ & $\begin{array}{l}3.899 * * * \\
(0.602)\end{array}$ & $\begin{array}{l}5.148 * * * \\
(0.662)\end{array}$ \\
\hline RiskPerception & $\begin{array}{l}-0.269 * * * \\
(0.076)\end{array}$ & $\begin{array}{l}-0.235^{\text {**** }} \\
(0.075)\end{array}$ & $\begin{array}{l}-0.227^{* * * *} \\
(0.074)\end{array}$ \\
\hline FinLitScore & & $\begin{array}{l}0.342^{* * * *} \\
(0.110)\end{array}$ & $\begin{array}{l}0.313^{* * * *} \\
(0.109)\end{array}$ \\
\hline FinancialRiskTolerance & & $\begin{array}{l}0.109^{*} \\
(0.057)\end{array}$ & $\begin{array}{l}-0.021 \\
(0.064)\end{array}$ \\
\hline FinancialLossTolerance & & $\begin{array}{l}0.031 \\
(0.056)\end{array}$ & $\begin{array}{l}0.037 \\
(0.055)\end{array}$ \\
\hline Female & & & $\begin{array}{l}-1.307^{\text {**** }} \\
(0.303)\end{array}$ \\
\hline $\mathrm{R}^{2}$ & 0.016 & 0.044 & 0.067 \\
\hline Adj. $R^{2}$ & 0.015 & 0.039 & 0.061 \\
\hline Num. obs. & 760 & 760 & 760 \\
\hline
\end{tabular}

${ }^{* * *} p<0.01 ;{ }^{* *} p<0.05 ;{ }^{*} p<0.1$. Standard errors in parentheses.

Table 5

OLS regression of subjects' period end wealth on subject risk and loss preferences $(0=$ very risk/loss averse, $10=$ not at all risk/loss averse).

\begin{tabular}{|c|c|c|c|}
\hline & PeriodEndWealth & PeriodEndWealth & PeriodEndWealth \\
\hline Intercept & $\begin{array}{l}1314.758^{* * * *} \\
(16.006)\end{array}$ & $\begin{array}{l}1308.987^{* * *} \\
(19.059)\end{array}$ & $\begin{array}{l}1344.964 * * * \\
(18.985)\end{array}$ \\
\hline FinLitScore & $\begin{array}{l}0.277 \\
(1.645)\end{array}$ & $\begin{array}{l}0.007 \\
(1.654)\end{array}$ & $\begin{array}{l}-0.133 \\
(1.635)\end{array}$ \\
\hline FinancialRiskTolerance & $\begin{array}{l}7.421^{* * *} \\
(2.845)\end{array}$ & $\begin{array}{l}7.530^{* * * *} \\
(2.852)\end{array}$ & $\begin{array}{l}3.262 \\
(2.644)\end{array}$ \\
\hline FinancialLossTolerance & $\begin{array}{l}-0.317 \\
(2.805)\end{array}$ & $\begin{array}{c}-0.352 \\
(2.793)\end{array}$ & $\begin{array}{l}-0.134 \\
(2.728)\end{array}$ \\
\hline RiskPerception & & $\begin{array}{l}1.495 \\
(1.912)\end{array}$ & $\begin{array}{l}1.790 \\
(1.905)\end{array}$ \\
\hline Female & & & $\begin{array}{l}-41.431^{\text {**** }} \\
(13.653)\end{array}$ \\
\hline $\mathrm{R}^{2}$ & 0.034 & 0.034 & 0.062 \\
\hline Adj. $R^{2}$ & 0.030 & 0.029 & 0.056 \\
\hline Num. obs. & 760 & 760 & 760 \\
\hline
\end{tabular}

${ }^{* * *} p<0.01,{ }^{* *} p<0.05,{ }^{*} p<0.1$. Standard errors, clustered at the subject level, in parentheses.

We use expected values to avoid distortions due to the ex-post realized random number, which remains unknown to our subjects while the market is open. Table 5 reports OLS regressions of subjects' period end wealth on subject characteristics. The first data column shows that final wealth is higher with higher financial risk tolerance, while financial literacy and loss tolerance are no significant drivers of final wealth. The second column adds RiskPercep- tion, but this has no significant effect and does not increase $R^{2}$. The third column adds a dummy variable for gender, approximately doubling the adjusted $R^{2}$, and documenting that women earn significantly lower profits. As our findings regarding women's asset holdings already led us to expect, the main driver for women's lower profits is that they are net sellers of assets, especially of those assets that were most underpriced compared to the risk- 
neutral BBV, i.e., the assets that were on average perceived to be the most risky. As a case in point, female subjects sell for an average price of 103.88 , while they buy for an average price of 110.64 (measured over all markets and assets). ${ }^{11}$ Hence, women on average sell below and buy above the unconditional expected value of 108.

With regard to our short-selling constraint, we observe that in only 11.3 percent of all cases (86 out of 760 subject $\times$ period combinations) did a given subject own zero shares at the end of a period. Since it is unclear in how many cases subjects actually would have gone short, this can be considered an upper bound on the number of cases where the short-selling constraint could potentially have played a role. The evidence on risk-averse preferences among our subjects suggests that many subjects likely ended up owning zero shares because they aimed to minimize the risk inherent in their final wealth position, not because they wanted to counteract high asset prices by selling as many shares as (and more than) they owned. This is supported by the fact that the average price across all assets was 107.36 and thus slightly below the unconditional expected buyback price of 108 . We therefore conclude that short-selling constraints are unlikely to have influenced our results.

\subsection{Robustness checks}

\subsubsection{Outliers and trading time}

Our analyses are conducted with data from all markets and periods (except for the single outlier mentioned in footnote ${ }^{8}$ ). To test the robustness of our results, we re-run all analyses and tests with three alternative datasets, with the results shown in three figures in the internet appendix.

In Robustness check I, learning from the outlier which happened in the first period of a market, we discard all data from the first period, to allow for the possibility that subjects still need to learn to work in the market environment. We thus only analyze data from periods 2 to 8 (see Fig. OA.18 in the online appendix). Furthermore, it might take some time for prices to settle in a market in any given period. Therefore, in Robustness check II we only look at data from the final $60 \mathrm{~s}$ of each of the 180 second-periods. This way we only look at prices once the market has more or less settled on an equilibrium for a period (see Figure OA.2 in the online appendix). Finally, in Robustness check III we combine the criteria from the first two robustness checks. Hence, we take only data from periods 2 to 8 and we furthermore analyze only transactions which occurred in the final $60 \mathrm{~s}$ of each period. We thus concentrate our analysis on the latest part of trading, where possible noise and confusion should be lowest (see Fig. OA.3 in the online appendix).

All three figures demonstrate that our results from the main analysis above also hold for each of the three robustness checks, as e.g. "probability of a loss" always has the highest $R^{2}$. We conclude that our general findings are robust to specific trading time and asset order.

\subsubsection{Salience of risk perception}

In addition to the robustness checks performed on the data from our main experiment, we also report on the results of three robustness check treatments. The first consists of five sessions of classroom experiments testing the role of the pre-trade risk elicitation on our results. In these five sessions, which we will refer to as treatment RETURN, instead of asking subjects "How risky do you perceive this security to be?" we ask "How attractive do you

\footnotetext{
${ }^{11}$ Male subjects buy for an average price of 101.95 and sell for an average price of 111.37 , thus generating positive net trading profits.
}

perceive the returns of this security to be?". The setup otherwise follows our main experiment in that each subject receives 5 assets and 800 cash at the beginning of each period, and one of the eight periods is randomly chosen to be relevant for payout.

The results corroborate our findings from the main experiment: perceived attractiveness decreases in assets' probability of loss $\left(R^{2}=0.94\right.$ at the asset level) and prices increase in perceived attractiveness $\left(R^{2}=0.60\right)$. Our results are thus not driven by our experimental setup directing subjects' focus to asset risk. Rather, subjects endogenously focus on probability of loss whenever they scrutinize the displayed distributions. (See Appendix B for replications of Figs. 2 and 3 for the data from treatment RETURN.)

\subsubsection{Trading experience}

In our next robustness check treatment, called treatment EXPERIENCE, instead of letting subjects trade each asset for one period only, we let subjects trade each asset for three consecutive periods. We furthermore do not elicit subjects' perceptions regarding the riskiness of the two assets in order not to direct subjects' attention to this asset characteristic. Finally, we limit the set of assets to NoLOSS and FrequentLOSS, which in the main experiment were characterized by, respectively, the highest and lowest prices (and vice versa for perceived riskiness). In nine markets of eight traders each, subjects first trade one asset for three periods, then trade the other for three periods (in five of the markets NoLOSS was traded first, in the other four FrequentLOSS was). The setup again follows our main experiment in that each subject receives 5 assets and 800 cash at the beginning of each period, and one of the six periods is randomly chosen to be relevant for payout.

The results corroborate our findings from the main experiment and from treatment RETURN: prices are significantly higher for NoLOSS than for FrequentLOSS in each of the three periods, with the difference not decreasing with repetition/experience (see Appendix $C$ for detailed analyses).

\subsubsection{Parallel trading}

In our third robustness check treatment, TWO-MARKETS, we let participants trade two assets simultaneously to test whether and how portfolio choice plays a role in pricing the assets. In line with the main experiment, and in contrast to treatment EXPERIENCE, we elicit subjects' perceptions regarding each asset's riskiness. Again we use only assets NoLOSS and FrequentLOSS for this treatment. As the task to trade two assets at the same time (on the same screen: one in the upper half of the screen, one in the lower; see Fig. OA.5 in the online appendix for a screenshot) causes a greater workload for traders, we extend the trading time from 3 to $4 \mathrm{~min}$. per period. To ensure enough liquidity we also increase the number of traders from 8 to 12 per market. We conduct ten markets where subjects simultaneously trade the two assets for three consecutive periods. At the start of each period each subject is endowed with 5 units of each of the two assets and with 1600 cash. Again we find patterns that are very similar to the findings from our main experiment and from treatment EXPERIENCE. ${ }^{12}$

We find that risk perceptions differ significantly between distributions. The mean risk perception (on our scale of 1 , or "not risky", to 7, or "very risky") over all subjects, periods and sessions for the NoLOSS asset is 1.67 while that for FrequentLOSS is 5.46 (Wilcoxon signed ranks test $V=5514.5, p=0.0000$; paired $t$-test $t(107)=23.82, p=0.0000)$.

\footnotetext{
12 In one session we experience price outliers for asset NoLOSS, which was traded at an average price of 235.09 (while asset FrequentLOSS traded at an average price of 129.53). To be consistent with our outlier exclusion in the main experiment, we eliminate this session from our data. Our findings remain qualitatively unchanged. Results that include the data from this outlier session are presented in Appendix D.
} 
We also find a significant difference in the average prices the two assets are traded for. The mean period price over all periods and sessions for the NoLOSS asset is 104.42 while that for FrequentLOSS is 97.08 (Wilcoxon signed ranks test $V=81, p=$ 0.01513 ; paired $t$-test $t(25)=2.336, p=0.0278)$. Turning to the three periods of trading each of the assets, average prices are 108.59, 102.20 and 102.94 in periods 1 through 3 for asset NoLOSS, and 98.17, 95.79 and 97.40 for asset FrequentLOSS. (See Appendix D for further details.)

Hence, with our robustness checks we show that our results are robust to analyzing only subsets of our data, to subjects' experience in trading the assets, to not cueing subjects to focus on risk perception prior to trading, and to individuals trading two assets simultaneously. We conclude that the results presented are robust and hold under several relevant conditions.

\section{Conclusion}

The question of how investors perceive risk is attracting increasing interest. The behavioral finance and decision making literature provides evidence that perceived riskiness is more strongly driven by one-sided risk measures such as the probability of incurring a loss (e.g. Klos et al., 2005; Nosić and Weber, 2010; Weber et al., 2013; Zeisberger, 2018) than by more "traditional" symmetric risk measures, such as the variance of returns. While these studies deliver valuable insights, they do not look beyond the individual investor-level in which decision-makers report self-stated risk perception, are price-takers and make a one-time investment decision.

We are instead interested in how individual perceptions affect market prices and trading behavior in asset markets. When investors use their orders to set prices on markets, individual beliefs, preferences and perceptions might cancel out or be diminished in the marketplace, and different risk-factors might drive asset prices. Or, on the contrary, these individual beliefs, preferences and perceptions may strongly influence and drive prices. Our paper is the first to analyze how risk perception affects prices and trading behavior in asset markets: we observed that average risk perception strongly influences asset prices. Furthermore, individual risk perception drives trading behavior and final asset holdings in markets.

Specifically, we find that the probability of suffering a loss when investing in a given asset, relative to a nominal value, drive participants' risk perception. This perception in turn drives market prices, as assets which are on average perceived as being more risky trade at lower prices. With a risk-neutral BBV of 108 , our eight assets trade at average prices of between 100 and 119 . With regard to individual trading behavior in markets we find that traders who perceive an asset to be relatively more risky trade out of it, while those who perceive it to be relatively less risky are net buyers. This holds even as prices already reflect differences in average risk perception. Consequently, asset prices and trading behavior in our experiments are driven by individual and average risk perception, and prices differ significantly for assets characterized by the same mean and standard deviation. Our results are robust to analyzing different subsets of our data, and they also hold for experienced traders and when traders can trade two assets at the same time.

Our findings differ from previously analyzed links between loss aversion and asset prices (see Ang et al., 2005 based on the disappointment aversion framework of Gul, 1991 or Barberis et al., 2001) as in our case, results are driven by the probability of suffer- ing a loss. Loss aversion more generally is not capable of capturing our findings. In this way our results support - in a market setting - findings of Levy and Levy (2009) who test such preferences experimentally but also show the theoretical implications for investments and asset pricing. They show, for example, that preferences found in our study on the market and individual level can explain about one third of the equity premium puzzle. Also, such preferences strongly influence asset pricing models, with investors holding primarily safe assets. However, the heterogeneity in risk perceptions and preferences makes it difficult to really infer market predictions from their results gained at the individual level, which is why we test these predictions in an experimental market setting.

We believe that our results are of interest for investors, financial professionals and regulators alike. With regard to risk characteristics, practitioners designing financial products may well be aware that investors understand "risk" to a large extent as the probability of incurring a loss, and that issuers can thus demand a premium when offering a product with supposedly low risk by ruling out losses (real losses due to inflation do of course occur, but seem to be neglected by many investors). This explains why socalled "guarantee products" (promising to pay back at least the full investment amount, while offering the chance of earning a positive return if some benchmark performs well) are very popular among investors and issuers alike.

Furthermore, our findings indicate that individual-level results regarding risk perception also affect market outcomes. When trying to better understand trading behavior and asset prices in financial markets, risk measures besides those hitherto in the spotlight may be more important than previously acknowledged. Consequently, in order to better understand and possibly predict market outcomes, risk perception data - rather than classically used risk measures alone - provide potentially valuable additional explanatory power. Hence, we see value in putting more emphasis on understanding how investors experience and perceive investment opportunities rather than on using more easily measurable objective risk metrics. One way to do so would be to use investor surveys and to also better tailor relevant questions to risk expectations and perception.

\section{Acknowledgements}

The authors thank the editor Geert Bekaert, the associate editor, two anonymous referees, Charlotte Borsboom, Erik Theissen, participants at Austrian Experimental Economics Workshop 2017 (Vienna), Austrian Working Group on Banking and Finance (Obergurgl), Chapman Conference on the Experimental and Behavioral Aspects of Financial Markets 2018 (Los Angeles), Economic Science Association 2017 (Vienna), Experimental Finance 2017 (Nice), research seminar participants in Bonn, Graz, Innsbruck, Mannheim, Stuttgart, Zurich and at Yale University for valuable feedback and Oliver Kirchkamp for incorporating custom functionality in his $\mathrm{R}$ import script for z-Tree output files. Funding by the Austrian Science Fund FWF (START-Grant Y617-G11 Kirchler and SFB-Grant F63 P4340-015-019 Huber) and the Oesterreichische Nationalbank (grant 14953 Huber) is gratefully acknowledged. 


\section{Appendix A}
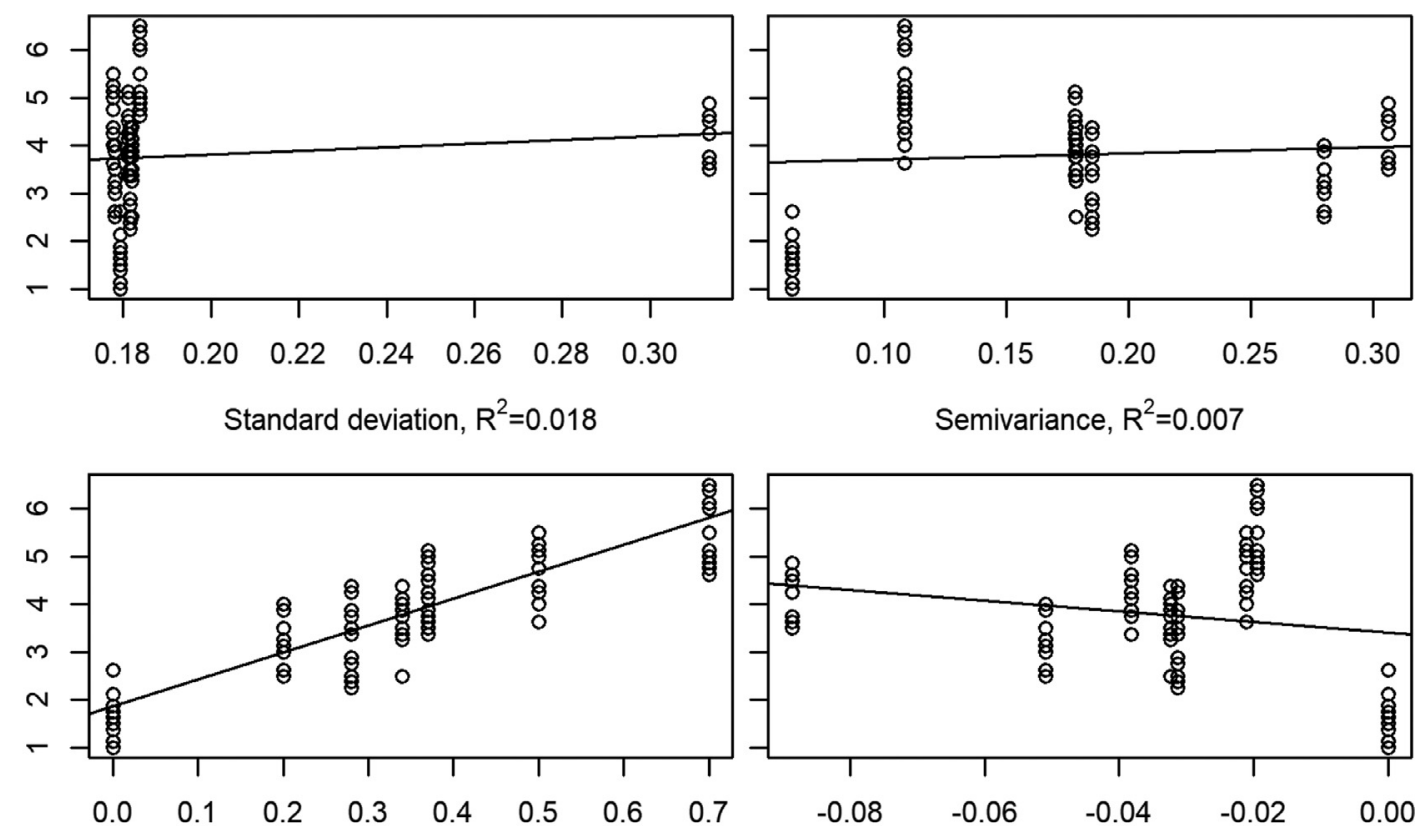

흔
$\frac{0}{0}$
$\frac{0}{0}$
$\frac{0}{0}$
$\frac{0}{\alpha}$
$\frac{5}{\alpha}$
$\frac{0}{\alpha}$

Probability of loss, $\mathrm{R}^{2}=0.773$

Expected loss, $\mathrm{R}^{2}=0.05$

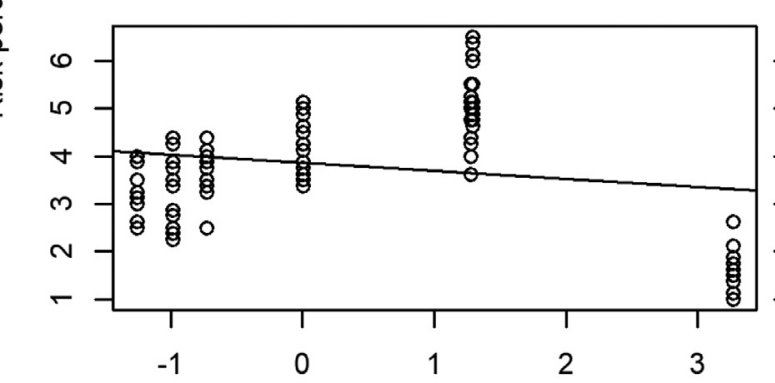

Skewness, $R^{2}=0.037$

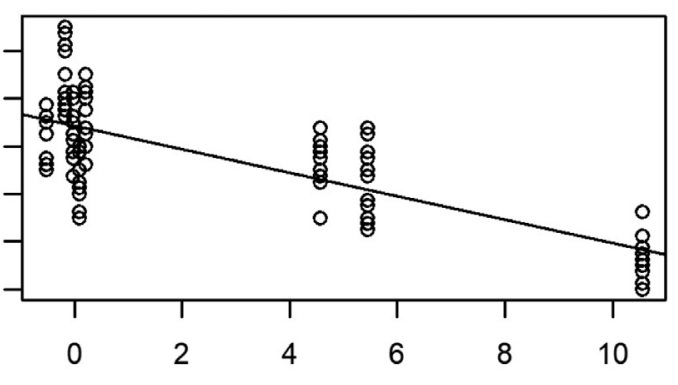

Kurtosis, $\mathrm{R}^{2}=0.55$

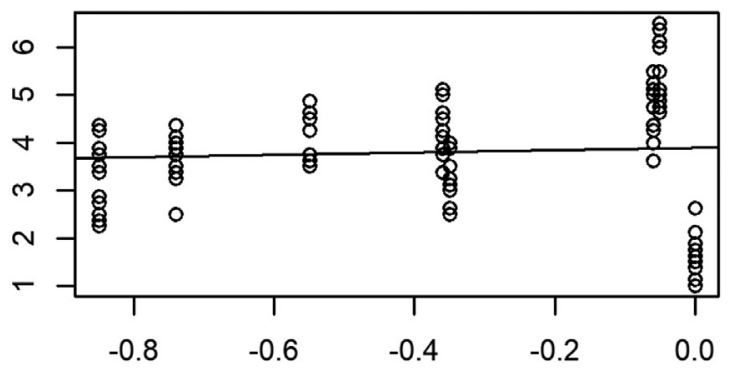

Minimum return, $\mathrm{R}^{2}=0.004$

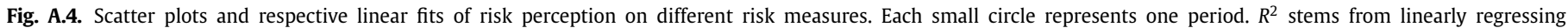
average risk perception on the respective risk measure. 


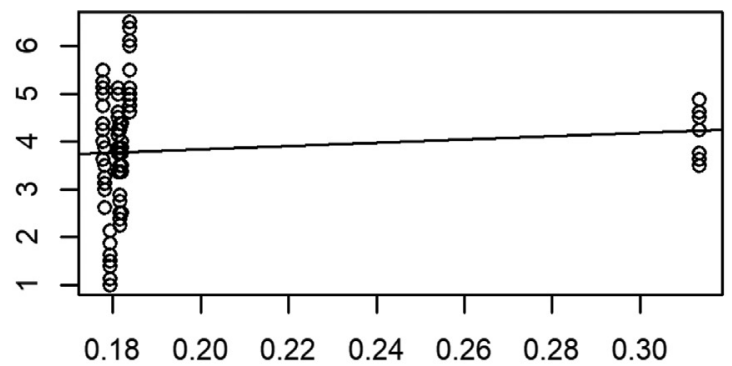

Standard deviation, $\mathrm{R}^{2}=0.016$

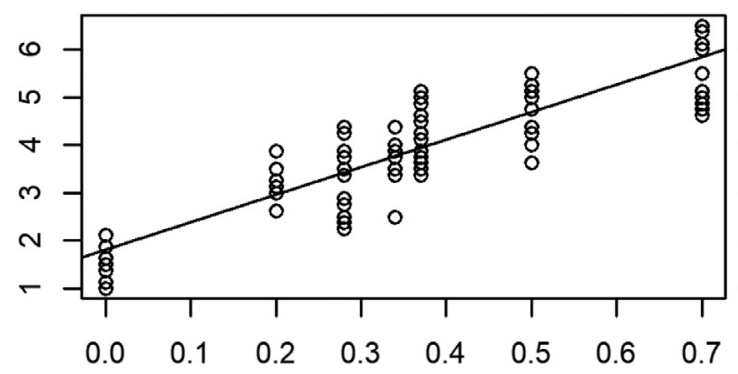

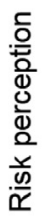

Probability of loss, $\mathrm{R}^{2}=0.771$

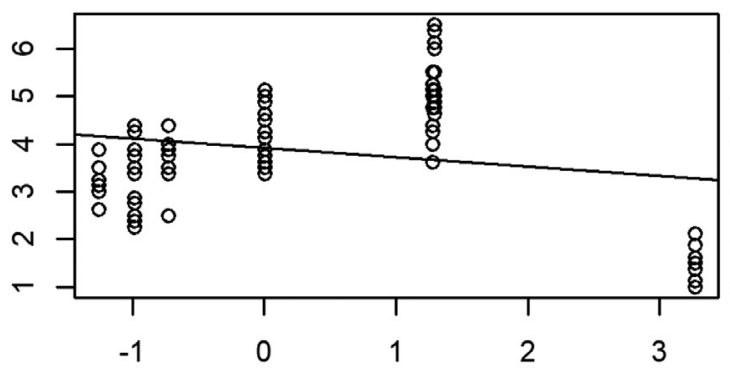

Skewness, $R^{2}=0.045$

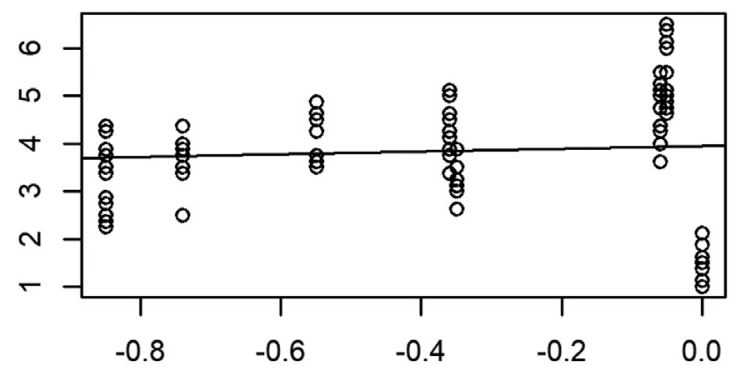

Minimum return, $\mathrm{R}^{2}=0.006$

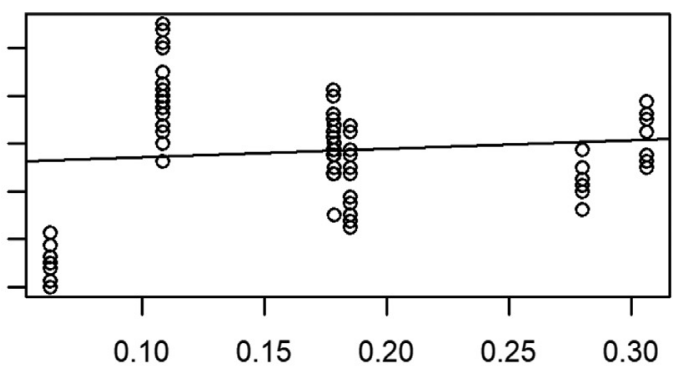

Semivariance, $\mathrm{R}^{2}=0.012$

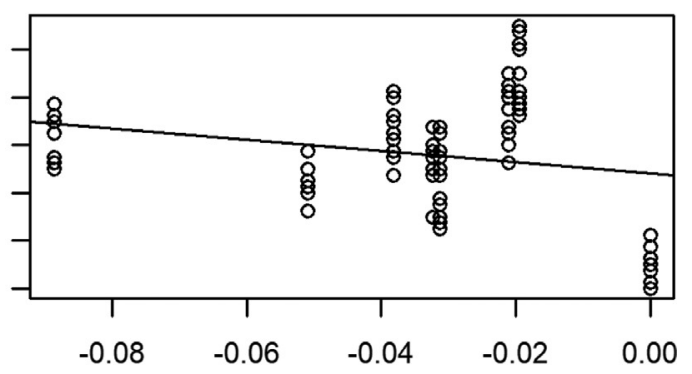

Expected loss, $\mathrm{R}^{2}=0.056$

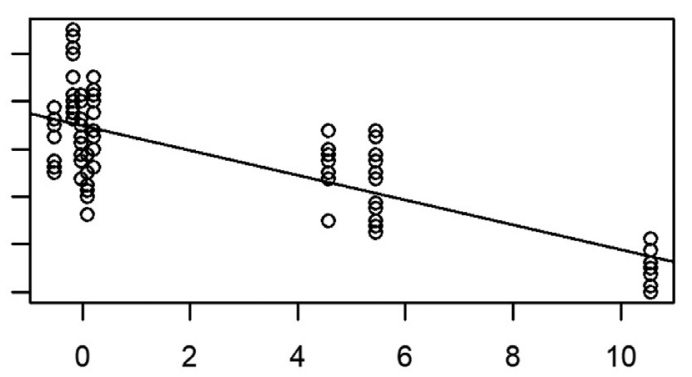

Kurtosis, $\mathrm{R}^{2}=0.588$

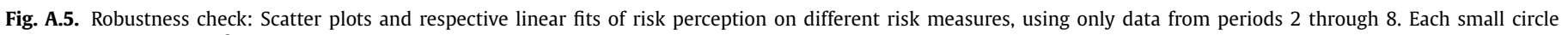
represents one period. $R^{2}$ stems from linearly regressing average risk perception on the respective risk measure. 

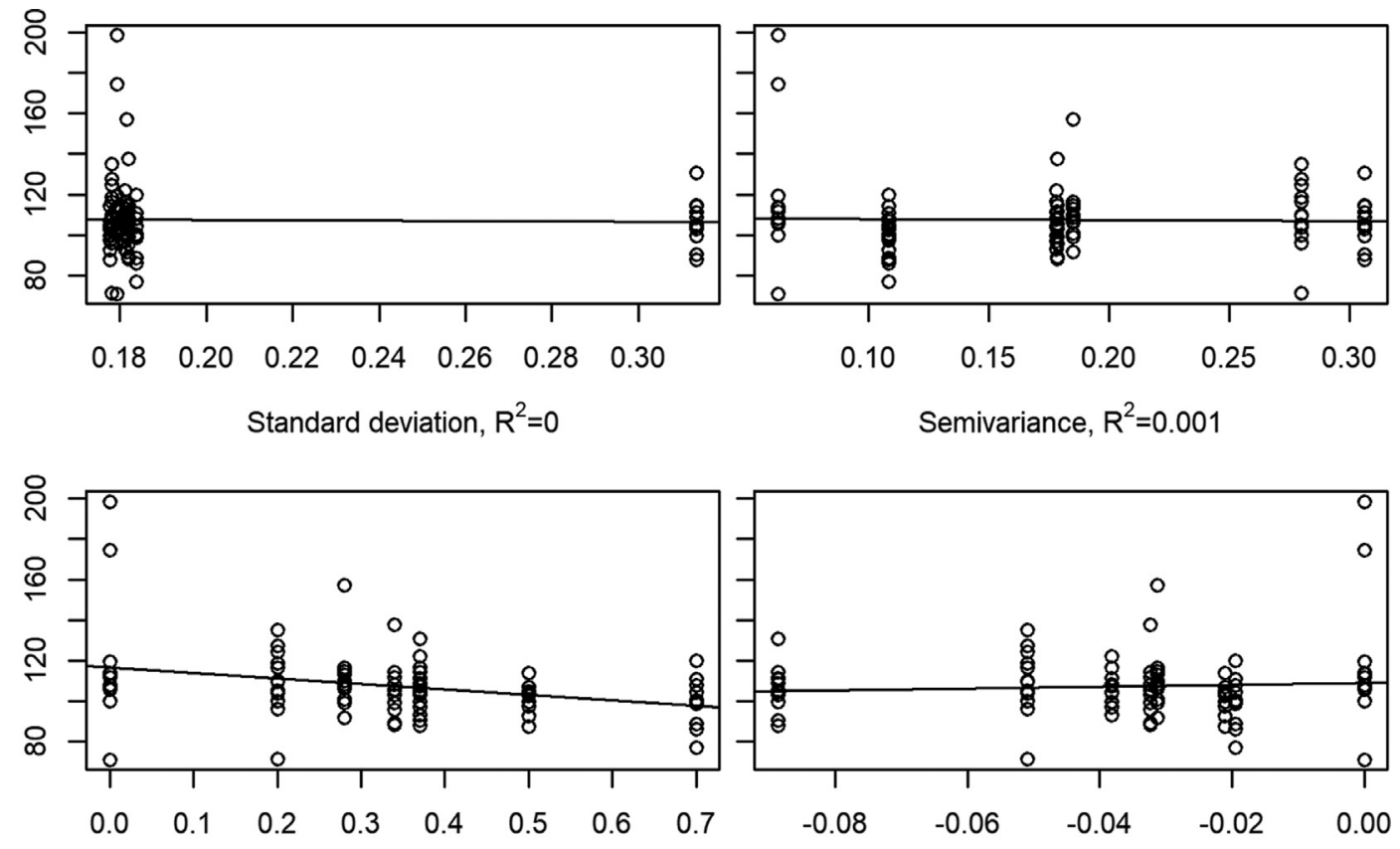

$Ð$
$\frac{0}{2}$
$\frac{1}{0}$
$\frac{0}{0}$
$\frac{0}{0}$
$\frac{1}{4}$

Probability of loss, $R^{2}=0.094$

Expected loss, $\mathrm{R}^{2}=0.005$
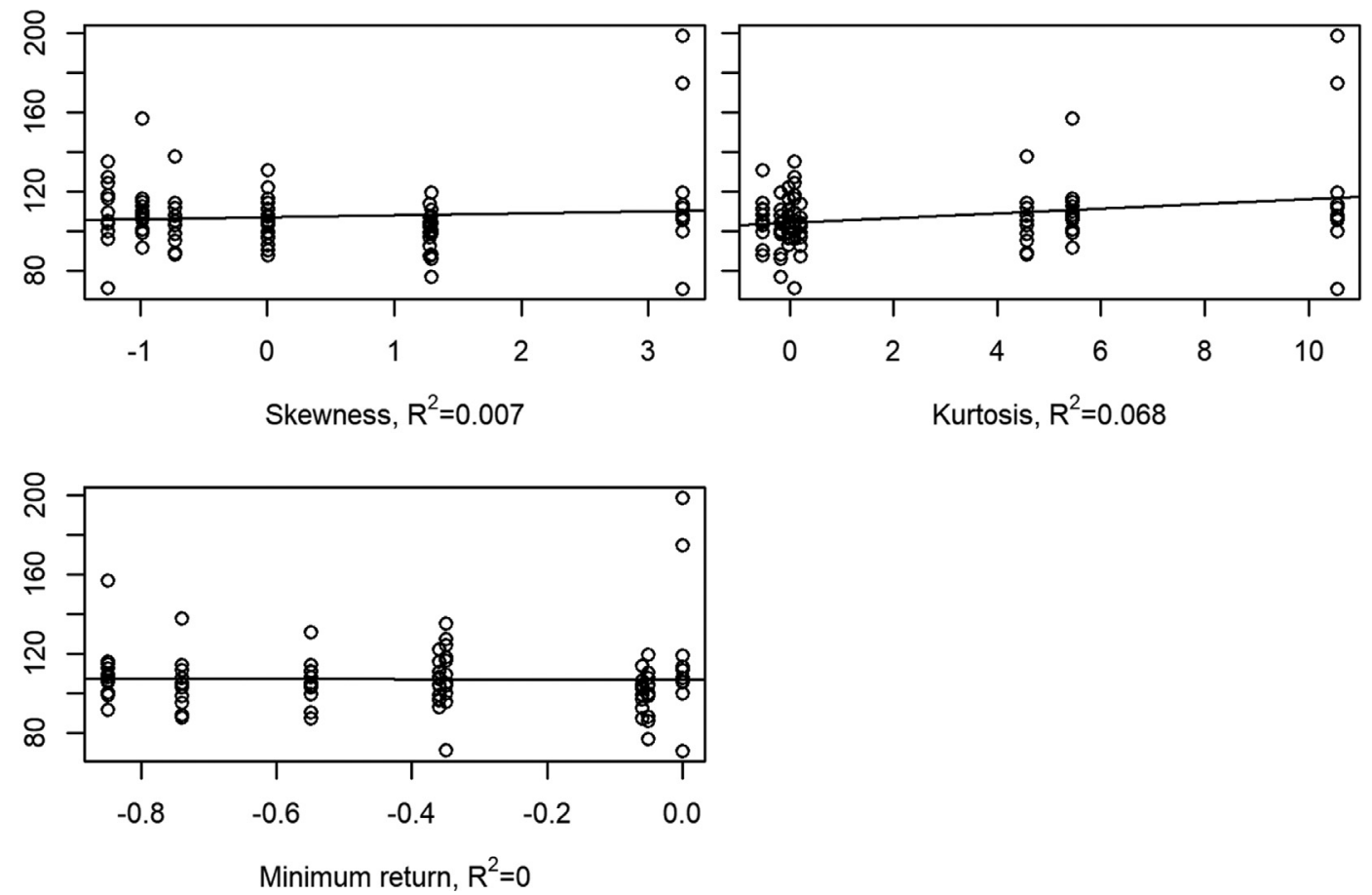

Fig. A.6. Scatter plots and respective linear fits of average price on different risk measures. Each small circle represents one period. $R^{2}$ stems from linearly regressing average price on the respective risk measure. 


\section{Appendix B. Results of robustness check treatment RETURN}

The following Fig. B.7 replicates Fig. 2 for the data from our RETURN treatment, and Fig. B.8 replicates Fig. 3. Taken together they confirm that an asset's probability of a loss drives risk and attractiveness perception, and that risk and attractiveness perception in turn drive market prices.
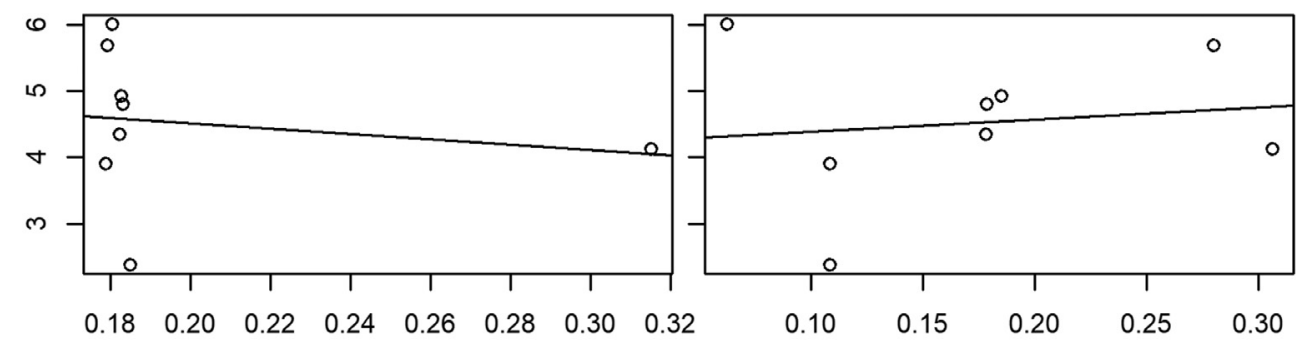

Standard deviation, $\mathrm{R}^{2}=0.028$

Semivariance, $\mathrm{R}^{2}=0.018$
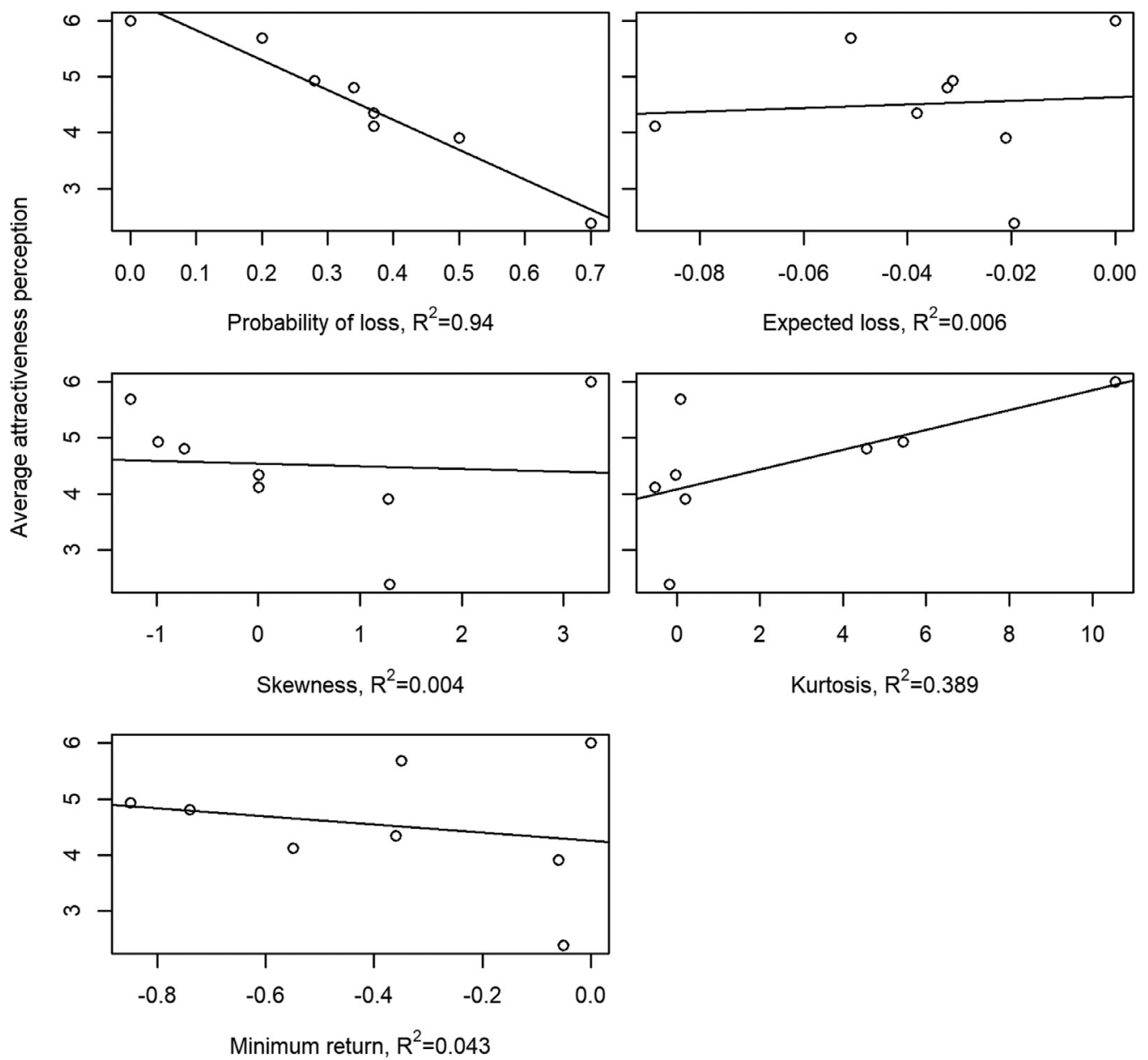

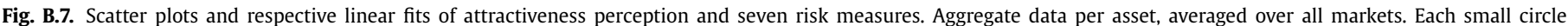
represents one of the eight traded assets. $R^{2}$ stems from linearly regressing average attractiveness perception on the respective risk measure. 


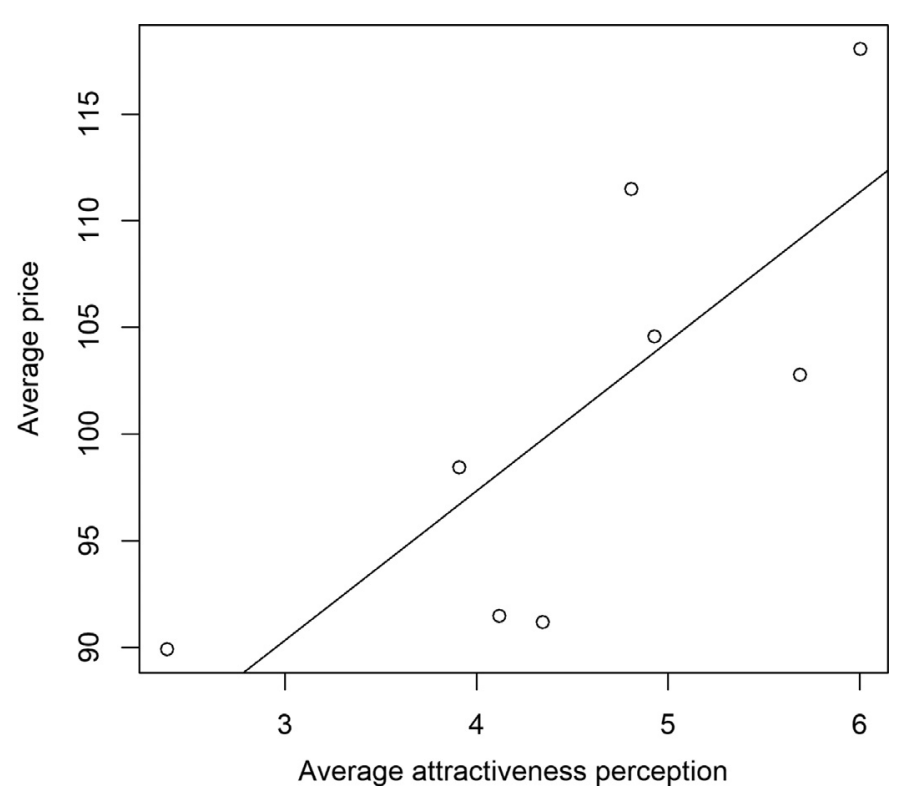

Fig. B.8. Distribution of average prices over average attractiveness perception. Aggregate data per asset, averaged over all markets. Each small circle represents one of the eight traded assets.

\section{Appendix C. Results of robustness check treatment EXPERIENCE}

Table C.6 documents that the asset NoLOSS is traded at significantly higher prices than asset FrequentLOSS and that this price difference does not vary across periods or with which asset is traded first.

Table C.6

Regressions of AvgPrice (per period) on a dummy variable for the NoLOSS distribution, a period ID variable within the block of three periods of trading the same asset, a dummy variable for the block being the second to be traded, and the interaction between the latter two variables.

\begin{tabular}{llll}
\hline & AvgPrice & AvgPrice & AvgPrice \\
\hline Intercept & $95.313^{* * *}$ & $98.665^{* * *}$ & $98.163^{* * *}$ \\
& $(1.974)$ & $(3.950)$ & $(5.520)$ \\
NoLOSS & $9.457^{* * *}$ & $9.457^{* * *}$ & $9.221^{* * *}$ \\
& $(2.792)$ & $(2.793)$ & $(2.845)$ \\
Period in block & & -1.676 & -0.836 \\
Second block & & $(1.711)$ & $(2.448)$ \\
& & & 1.240 \\
Period in block $\times$ Second block & & & $(7.486)$ \\
& & & -1.681 \\
$\mathrm{R}^{2}$ & 0.181 & 0.196 & 0.209 \\
Adj. $\mathrm{R}^{2}$ & 0.165 & 0.164 & 0.144 \\
Num. obs. & 54 & 54 & 54 \\
\hline
\end{tabular}

${ }^{* * *} p<0.01 ;{ }^{* *} p<0.05 ;{ }^{*} p<0.1$. Standard errors in parentheses.

\section{Appendix D. Results of robustness check treatment TWO-MARKETS}

We start by providing further details on our findings from the TWO-MARKETS treatment by presenting a figure and regressions based on the data excluding the outlier session. Fig. D.9 compares average period prices to average risk perception. Each circle represents one trading period. The slightly downward sloping line stems from a linear fit of the data. Prices decrease in risk aversion.

Table D.7

OLS and session fixed effects panel regressions of average prices across assets. Standard errors clustered at the session level, in parentheses.

\begin{tabular}{lll}
\hline & AvgPrice (OLS) & AvgPrice (FE) \\
\hline Intercept & $97.789^{* * *}$ & \\
NoLOSS & $(7.354)$ & \\
& $12.249^{* *}$ & $12.249^{* * *}$ \\
Period & $(4.946)$ & $(4.524)$ \\
& -0.347 & -0.554 \\
NoLOSS $\times$ Period & $(1.817)$ & $(1.529)$ \\
& -2.406 & -2.406 \\
$\mathrm{R}^{2}$ & $(1.717)$ & $(1.570)$ \\
Adj. $\mathrm{R}^{2}$ & 0.091 & 0.328 \\
Num. obs. & 0.034 & 0.143 \\
\hline
\end{tabular}

*** $p<0.01 ;{ }^{* *} p<0.05 ;{ }^{*} p<0.1$. Standard errors in parentheses.

Table D.7 documents that the asset NoLOSS is priced significantly more highly than asset FrequentLOSS and that this price difference does not vary across periods.

If we include the outlier session in our data analysis, we find the following: The mean risk perception (on our scale of 1, or "not risky", to 7, or "very risky") over all subjects, periods and sessions for the NoLOSS asset is 1.65 (instead of 1.67) while that for FrequentLOSS is 5.48 (instead of 5.46) (Wilcoxon signed ranks test $V=6847.5, p=0.0000$, paired $t$-test $t(119)=26.073, p=0.0000)$.

The mean period price over all periods and sessions for the NoLOSS asset is 117.80 (instead of 104.42) while that for FrequentLOSS is 100.45 (instead of 97.08) (Wilcoxon signed ranks test $V=95, p=0.0069$, paired $t$-test $t(28)=1.9087, p=0.0666$ ). Turning to the three periods of trading each of the assets, average prices are $118.24,117.44$ and 117.76 instead of (108.59, 102.20, 102.94) in periods 1 through 3 for the asset NoLOSS, and 102.03, 99.82 and 99.65 instead of $(98.17,95.79,97.40)$ for the asset FrequentLOSS. 


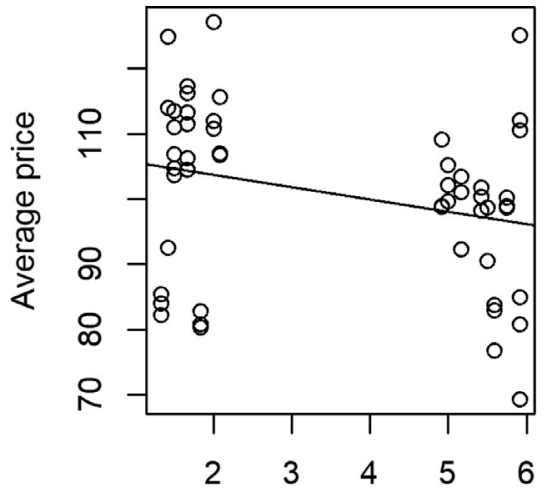

Average risk perception, $\mathrm{R}^{2}=0.075$

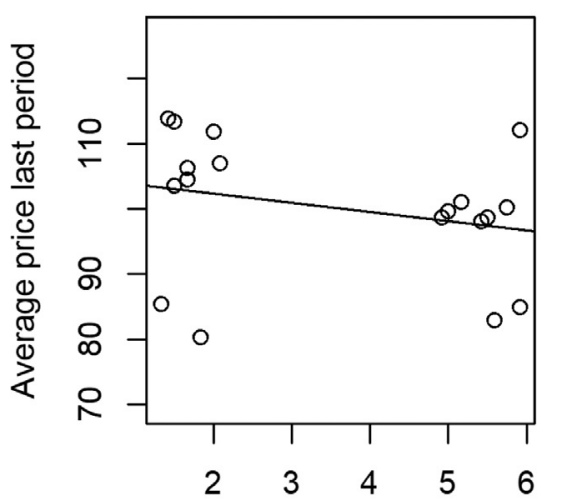

Average risk perception, $\mathrm{R}^{2}=0.071$

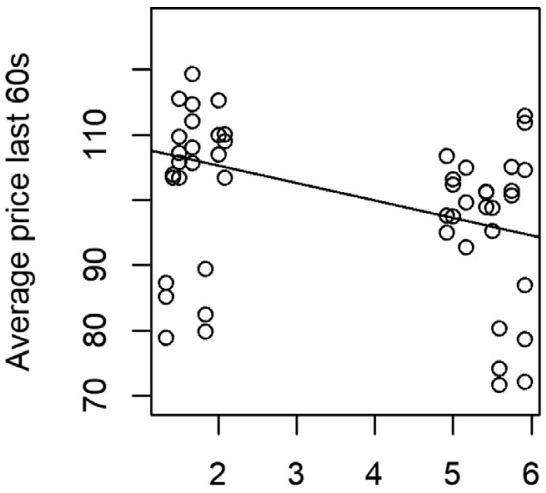

Average risk perception, $\mathrm{R}^{2}=0.119$

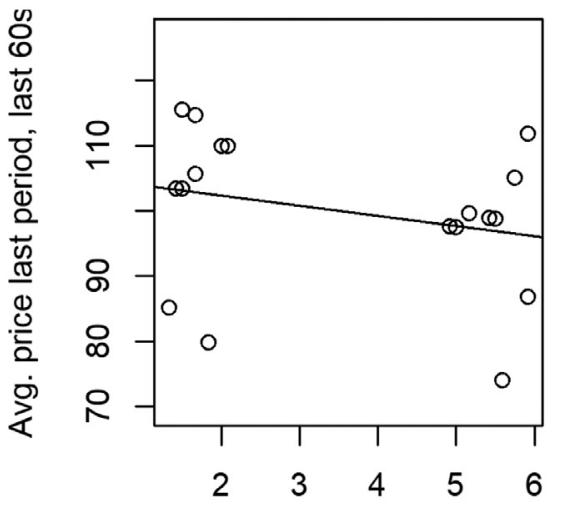

Average risk perception, $\mathrm{R}^{2}=0.068$

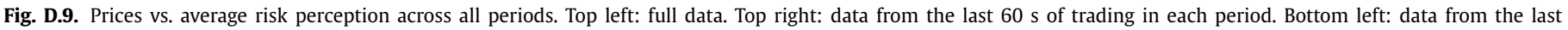
trading period in each session only. Bottom right: data from the last $60 \mathrm{~s}$ in the last trading period in each session only.

\section{Supplementary material}

Supplementary material associated with this article can be found, in the online version, at doi:10.1016/j.jbankfin.2019.105635.

\section{References}

Ackert, L., Church, B., Qi, L., 2016. An experimental examination of portfolio choice. Rev. Financ. 20 (4), 1427-1447.

Ang, A., Bekaert, G., Liu, J., 2005. Why stocks may disappoint. J. Financ. Econ. 76 (3), 471-508.

Barber, B., Odean, T., Zhu, N., 2008. Do retail trades move markets? Rev. Financ. Stud. 22, 151-186.

Barberis, N., Huang, M., Santos, T., 2001. Prospect theory and asset prices. Q. J. Econ. $116,1-53$

Baucells, M., Rata, C., 2006. A survey study of factors influencing risk-taking behavior in real-world decisions under uncertainty. Decis. Anal. 3 (3), 163-176.

Benartzi, S., Thaler, R.H., 1995. Myopic loss aversion and the equity premium puzzle. The Q. J. Econ. 110 (1), 73-92.

Bock, O., Baetge, I., Nicklisch, A., 2014. hroot: Hamburg registration and organization online tool. Eur. Econ. Rev. 71, 117-120. doi:10.1016/j.euroecorev.2014.07.003.

Brachinger, H.W., Weber, M., 1997. Risk as a primitive: a survey of measures of perceived risk. Oper. Res. Spektrum 19 (4), 235-250.

Bradbury, M., Hens, T., Zeisberger, S., 2015. Improving investment decisions with simulated experience. Rev. Financ. 19, 1019-1052.

Coval, J.D., Shumway, T., 2005. Do behavioral biases affect prices? J. Financ. 60, 1-34.

Diecidue, E., Van De Ven, J., 2008. Aspiration level, probability of success and failure, and expected utility. Int. Econ. Rev. 49 (2), 683-700.

Dohmen, T.J., Falk, A., Huffman, D., Schupp, J., Sunde, U., Wagner, G., 2011. Individual risk attitudes: measurement, determinants, and behavioral consequences. J. Eur. Econ. Assoc. 9 (3), 522-550.

Ehm, C., Laudenbach, C., Weber, M., 2018. Focusing on volatility information instead of portfolio weights as an aid to investor decisions. Exp. Econ. 21 (2), 457-480.

Fischbacher, U., 2007. Z-tree: zurich toolbox for ready-made economic experiments. Exp. Econ. 10 (2), 171-178.

Gode, D.K., Sunder, S., 1993. Allocative efficiency of markets with zero-intelligence traders: market as a partial substitute for individual rationality. J. Polit. Econ. 101 (1), 119-137.
Gul, F., 1991. A theory of disappointment aversion. Econometrica 59 (3), 667-686. Heemeijer, P., Hommes, C., Sonnemans, J., Tuinstra, J., 2009. Price stability and volatility in markets with positive and negative expectations feedback: an experimental investigation. J. Econ. Dyn. Control 33, 1052-1072.

Hirshleifer, D., 2015. Behavioral finance. Ann. Rev. Financ. Econ. 7, 133-159.

Holzmeister, F., Huber, J., Kirchler, M., Lindner, F., Weitzel, U., Zeisberger, S., 2019. What drives risk perception? A global survey with financial professionals and lay people. SSRN Working Paper (no. 3374893).

Hommes, C., 2011. The heterogenous expectations hypothesis: some evidence from the lab. J. Econ. Dyn. Control 35 (1), 1-24.

Keller, L.R., Sarin, R.K., Weber, M., 1986. Empirical investigation of some properties of the perceived riskiness of gambles. Org. Behav. Hum. Decis. Process. 38 (1), 114-130.

Kirchkamp, O., 2019. Importing z-tree data into R. J. Behav. Exp. Financ. 22, 1-2. doi:10.1016/j.jbef.2018.11.008.

Kirchler, M., Huber, J., Stöckl, T., 2012. Thar she bursts - reducing confusion reduces bubbles. Am. Econ. Rev. 102 (2), 865-883.

Klos, A., Weber, E.U., Weber, M., 2005. Investment decisions and time horizon: risk perception and risk behavior in repeated gambles. Manag. Sci. 51 (12), 1777-1790.

Koonce, L., McAnally, M.L., Mercer, M., 2005. How do investors judge the risk of financial items? The Account. Rev. 80 (1), 221-241.

Kroll, Y., Levy, H., Rapoport, A., 1988. Experimental tests of the mean-variance model for portfolio selection. Org. Behav. Hum. Decis. Process. 42, 388-410.

Leifeld, P., 2013. Texreg: conversion of statistical model output in $r$ to LaTeX and HTML tables. J. Stat. Softw. 55 (8), 1-24 http://www.jstatsoft.org/v55/i08/.

Levy, H., Levy, M., 2009. The safety first expected utility model: experimental evidence and economic implications. J. Bank. Financ. 33, 1494-1506.

Lintner, J., 1965. The valuation of risk assets and the selection of risky investment in stock portfolios and capital budgets. Rev. Econ. Stat. 47 (1), 13-37.

MacGregor, D.G., Slovic, P., Berry, M., Evensky, H., 1999. Perception of financial risk: a survey study of advisors and planners.. J. Financ. Plan. 12 (8), 68-86.

Markowitz, H., 1952. Portfolio selection. J. Financ. 7 (1), 77-91.

Merkle, C., 2018. The curious case of negative volatility. J. Financ. Mark. 40, 92-108 Mossin, J., 1966. Equilibrium in a capital asset market. Econometrica 34 (4), 768-783.

Nosić, A., Weber, M., 2010. How riskily do i invest? The role of risk attitudes, risk perceptions, and overconfidence. Decis. Anal. 7 (3), 282-301.

Noussair, C.N., Tucker, S., 2016. Cash inflows and bubbles in asset markets with constant fundamental values. Econ. Inquiry 54 (3). doi:10.1111/ecin.12320. 
Palan, S., 2015. GIMS - software for asset market experiments. J. Behav. Exp. Financ. 5, 1-14. doi:10.1016/j.jbef.2015.02.001.

R Core Team, 2018. R: A language and environment for statistical computing. $\mathrm{R}$ Foundation for Statistical Computing. Vienna, Austria. https://www.R-project. org/.

Rettinger, D.A., Hastie, R., 2001. Content effects on decision making. Org. Behav. Hum. Decis. Process. 85 (2), 336-359.

van Rooij, M., Lusardi, A., Alessie, R., 2011. Financial literacy and stock market participation. J. Financ. Econ. 101, 449-472.

Roy, A., 1952. Safety first and the holding of assets. Econometrica 20 (3), 431449.

Sharpe, W., 1964. Capital asset prices: a theory of market equilibrium under conditions of risk. J. Financ. 19 (3), 425-442.

Shefrin, H., 2008. A Behavioral Approach to Asset Pricing. Academic Press/Elesevier.

Tversky, A., Kahneman, D., 1992. Advances in prospect theory: cumulative representation of uncertainty. J. Risk Uncertain. 5, 297-323.
Unser, M., 2000. Lower partial moments as measures of perceived risk: an experimental study. J. Econ. Psychol. 21 (3), 253-280.

Veld, C., Veld-Merkoulova, Y.V., 2008. The risk perceptions of individual investors. J. Econ. Psychol. 29 (2), 226-252.

Weber, E.U., Blais, A.-R., Betz, N.E., 2002. A domain-specific risk-attitude scale: measuring risk perceptions and risk behaviors. J. Behav. Decis. Making 15 (4), 263-290.

Weber, E.U., Siebenmorgen, N., Weber, M., 2005. Communicating asset risk: how name recognition and the format of historic volatility information affect risk perception and investment decisions. Risk Anal. 25 (3), 597-609.

Weber, M., Weber, E., Nosić, A., 2013. Who takes risks when and why: determinants of changes in investor risk-taking. Rev. Financ. 17 (3), 847-883.

Zeisberger, S., 2016. People do care about loss probabilities? Working Paper, https: //papers.ssrn.com/abstract=2169394.

Zeisberger, S., 2018. What is risk? how investors perceive risk in return distributions. Working Paper, https://ssrn.com/abstract=2811636. 